\title{
ASSESSMENT OF GEOPHYSICAL LOGS FROM BOREHOLE USW G-2, YUCCA MOUNTAIN,
}

NEVADA

by Philip H. Nelson and Ulrich Schimschal

\section{U.S. GEOLOGICAL SURVEY}

Open-File Report 92-572

Prepared in cooperation with the NEVADA FIELD OFFICE

U.S. DEPARTMENT OF ENERGY

(Interagency Agreement DE-AI08-92NV10874) 


\title{
DEPARTMENT OF THE INTERIOR BRUCE BABBITT, Secretary
}

\author{
U.S. GEOLOGICAL SURVEY \\ DALLAS L. PECK, Director
}

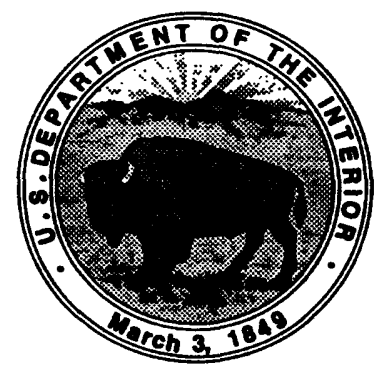

Any use of trade names in this publication is for descriptive purposes only and does not imply endorsement by the U.S. Geological Survey.

For additional information write to Chief, Geologic Studies Program Yucca Mountain Project Branch U.S. Geological Survey Box 25046, Mail Stop 421

Denver Federal Center Denver, CO 80225-0046

For sale by the Books and Open-File Reports Section U.S. Geological Survey Federal Center, Box 25425

Denver, Colorado 80225 


\section{CONTENTS}

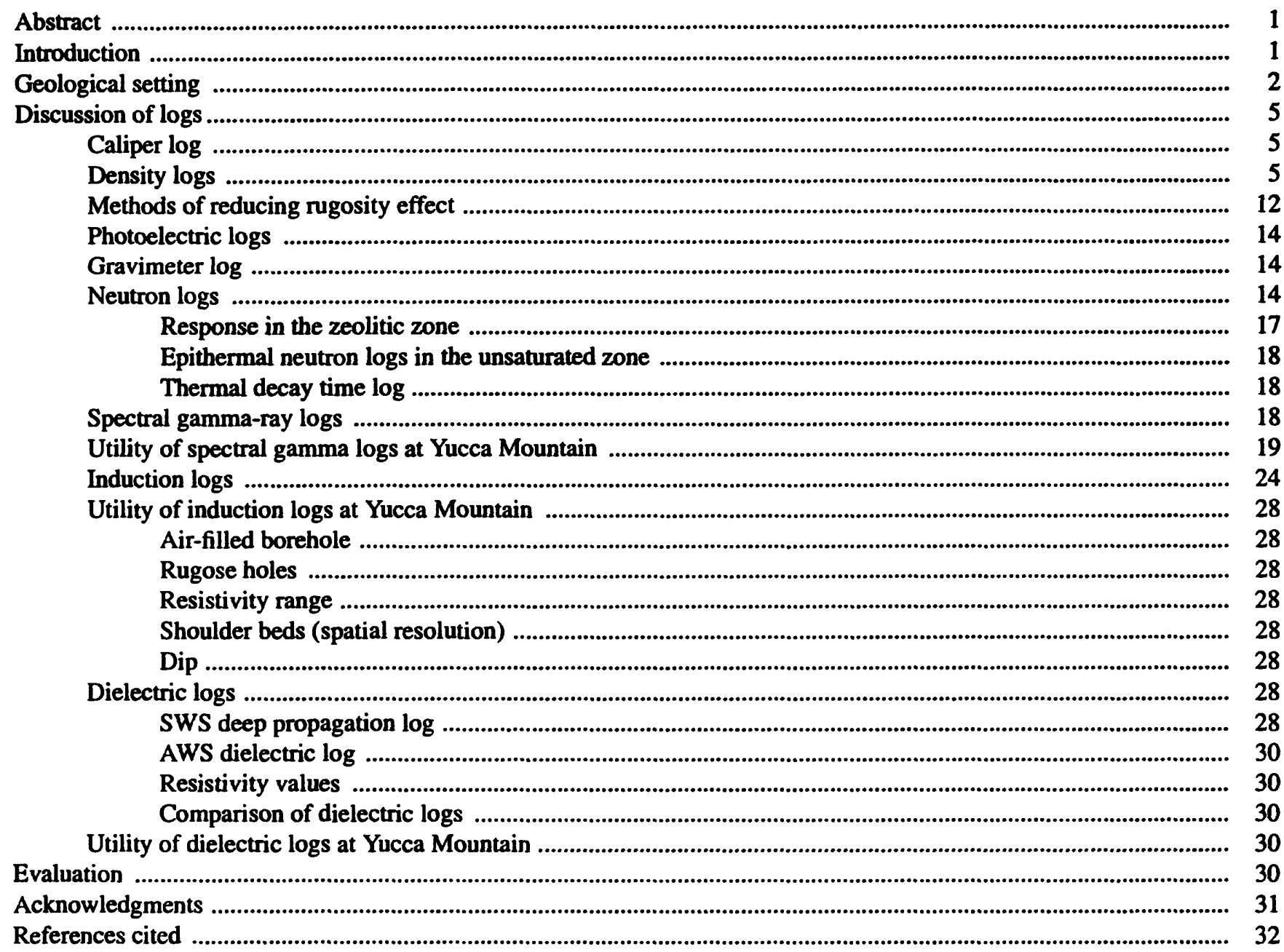

\section{FIGURES}

1. Graph showing geological information and four representative logs.

2. Diagram showing detailed sections of the AWS six-arm caliper log from the unsaturated zone and 3-16. Gaphs showing:

3. Caliper (AVG), five density logs, and two photoelectric logs in the unsaturated zone .............................

4. Expanded view of caliper, five density logs, and two photoelectric logs across

the boundary at 1,750 feet between the saturated and unsaturated zones...

5. SWS and AWs density logs shown with densities computed from core data

6. Four density logs over the interval 900 to 1,300 feet

7. Density derived from borehole gravimeter run compared with gamma-gamma logs

with gamma-gamma logs............................... 13

8. Neutron and caliper logs from the saturated zone ................................................................................... 15

9. Epithermal neutron and caliper logs from the unsaturated zone ............................................................ 16

10. Caliper, total gamma ray, and potassium, uranium, and thorium logs .................................................. 20

11. Potassium, uranium, and thorium estimates from spectral gamma ray tools, in air-filled borehole ........... 21

12. Potassium, uranium, and thorium logs from AWS repeat and main runs.................................................... 22

13. Thorium, uranium, and potassium logs from four SWS NGT runs ..................................................... 23 
3-16. Graphs showing--Continued:

14. Traces from induction tools run in the saturated zone by SWS and AWS

15. Deep and medium induction logs run in the unsaturated zone by SWS, AWS, and Birdwell in 1981

16. Resistivity and dielectric logs at $25 \mathrm{MHz}$ and at $47 \mathrm{MHz}$

\section{TABLES}

1. Summary of logs collected in borehole G-2, January 1991

2. Average density and standard deviation $\left(\mathrm{g} / \mathrm{cm}^{3}\right)$ over four depth intervals (feet) for six density tools .

3. Mean and standard deviation $\left(\mathrm{g} / \mathrm{cm}^{3}\right)$ over the depth interval $1,750-2,000$ feet (water-filled borehole)

4. Neutron logs run in water-filled borehole $(1,750-2,650$ feet $)$ in zeolitic tuff

5. Mean/range of thorium, uranium and potassium from 9-minute runs at selected depths using SWS's NGT tool

6. Resistivity (ohm-m) and, in parentheses, conductivity ( $\mathrm{mmho} / \mathrm{m})$ from the SWS IDPH trace at three depths and three frequencies

\section{CONVERSION FACTORS}

\begin{tabular}{rll}
\hline Multiply & By & To obtain \\
\hline centimeter $(\mathrm{cm})$ & & inch \\
meter $(\mathrm{m})$ & 0.3937 & foot \\
foot $(\mathrm{ft})$ & 3.281 & meter
\end{tabular}




\title{
Assessment of Geophysical Logs from Borehole USW G-2, Yucca Mountain, Nevada
}

\author{
By Philip H. Nelson, U.S. Geological Survey, and \\ Ulrich Schimschal, U.S. Bureau of Reclamation
}

ABSTRACT

Commercial logging contractors, Western Atlas, Schlumberger, and Edcon obtained borehole geophysical logs at the site of a potential high level nuclear waste repository at Yucca Mountain, Nevada. Drill hole USW-G2 was picked for this test of suitable logging tools and logging technology, both representing stateof-the-art technology by these commercial companies. Experience gained by analysis of existing core data and a variety of logs obtained earlier by Birdwell and Dresser Atlas served as a guide to a choice of logs to be obtained. Logs were obtained in water-filled borehole in zeolitized tuff (saturated zone) and in air-filled borehole largely in unaltered welded tuff (unsaturated zone).

Specific observations regarding tool performance include the following. The two dielectric tools agree very well; either tool will provide a valuable log for water saturation estimates. Density estimates from the gammagamma logs generally agree within $0.02 \mathrm{~g} / \mathrm{cm}^{3}$; more effort is needed to refine and document a correction for air-filled boreholes. Induction tool performance was not satisfactory; the 40 $\mathrm{kHz}$ tool is preferred because it offers the highest frequency and hence the highest signal to noise ratio, but requires careful work to minimize offset. Epithermal neutron tools provide useful data in the unsaturated zone, in particular one company's conversion to water-filled porosity gave realistic values when compared with core data. The gravimeter provides density values unaffected by borehole rugosity, but the estimate of free-air gradient remains a problem. The six-arm caliper provides information on borehole shape not otherwise available. These and other observations provide guidance for specifying tools to be run in future logging operations at Yucca Mountain.

\section{INTRODUCTION}

Well logs provide a critical source of information on rock properties, presented on a continuous basis as a function of depth. As part of the evaluation of Yucca Mountain as a potential waste repository, logs were obtained in forty boreholes during the time period 1978-1985 (Nelson, Muller and others, 1991). With drilling at Yucca Mountain now recommencing, an assessment of current logging technology is required to specify the kinds of logs and, if appropriate, the supplier and models of logging tools to be used in future logging.

The goals of logging at Yucca Mountain, broadly stated, are "(1) to aid in the definition and refinement of the location and character of lithostratigraphic units and contacts between units and (2) to determine the distribution of rock properties within lithostratigraphic units." (U.S. Department of Energy, 1988). The second goal implies the quantification of physical properties important to those assessing hydrological performance of the site, in particular, the determination of porosity and water saturation. These two quantities are routinely estimated from logs in petroleum exploration and production; our goal is to apply the logs and techniques to the environment at Yucca Mountain. Peculiarities of this environment are:

1. The upper portion ( 1,000 feet or more) lies above the water table and is partially saturated with low-salinity water. It is referred to as the unsaturated zone, or UZ.

2. The boreholes in the $U Z$ are air-filled rather than fluid-filled.

3. The boreholes are often very rugose, that is, the wellbore is not smooth.

4. The host rock is tuff. Some sections of the tuff are extensively altered to zeolite and clay; others contain lithophysae (vugs) which must be accounted for in evaluating density and porosity.

As pointed out by Nelson, Muller, and others (1991), these conditions lead to a number of complications not normally encountered in petroleum usage: 
1. The partially saturated welded tuff, which would host the potential repository, has high (1000 ohm-m) electrical resistivity. As a consequence, signals from the induction and dielectric tools are low, and accuracy is impaired.

2. Some conventional tools, particularly the sonic, electrical (electrode-bearing) resistivity, and long-spaced thermal neutron tools, cannot operate in air-filled holes. Others, like the density, suffer in terms of performance. And in most cases, algorithms developed for fluid-filled boreholes require modification for use in air-filled holes.

3. Rugosity creates an air gap between the sidewall tools and the rock. The effect on the density tool is particularly detrimental.

4. The physical properties of tuff must be investigated before log-based quantities can be converted to physical properties. The high water content of zeolitic tuffs cause the count rates of the long-spaced thermal neutron tools to be so low that repeatability is impaired, as shown in this report. Zeolites and clays also reduce the electrical resistivity, which does not cause any measurement problem, but does cause difficulties in interpretation. Laboratory results for density, electrical, and sonic properties are discussed by Nelson and Anderson (1992).

In this report, the term "thermal neutron tools" refers to conventional oil-field designs in which source and detector are separated by a foot or more. Another class of thermal neutron tools with close source-detector spacing has been used successfully in air-filled boreholes at Yucca Mountain (A. Flint, oral commun., 1992). This latter class is often referred to as "neutron moisture meters" and was developed for use in soil studies. The two types have completely different characteristics; for example, the count rate from a short-spaced detector increases as water-saturated porosity increases, but the count rate of a long-spaced detector has the opposite behavior (Tittman, 1956). The logs reported upon here are of the long-spaced class; conclusions reached regarding this class are not relevant to the performance of the short-spaced detector systems.
In January 1991, Schlumberger Well Services (SWS) and Atlas Wireline Services (AWS) ran logs in borehole G-2, over the interval 800 to 2,630 feet. The chronology and operational aspects of these logging runs have been reported by SAIC (1991a, 1991b). The supplier, the name of the logging run, and the measurements provided as individual traces are given in table 1. Borehole G-2 is located roughly $2,300 \mathrm{~m}$ north of the northern extremity of the potential repository at N778824, E560504 (Nevada State coordinates).

In addition to the logs listed in table $1, \mathrm{SWS}$ ran a tool referred to as the GLT (geochemical logging tool), which combines natural gamma ray spectrometry and neutron-induced gamma ray spectrometry to obtain a total of ten chemical elements. These data require further processing before they can be assessed, and are not considered in this report.

This collection of logs provides an opportunity to assess the performance of state-of-the-art logging tools. In this document we examine individual logs, pointing out obvious failure where it occurs, compare the numerical results between comparable tools from AWS and SWS, compare the logs obtained with core results from G-2, and display some older existing logs from G-2 for comparison with the 1991 data.

\section{GEOLOGICAL SETTING}

The mineralogy, lithology, and four logs representative of those obtained in January 1991 are shown in figure 1 . The logging interval was restricted by a plug at 2,645 feet and casing from surface to 800 feet. The geological units are: Topopah Spring Member of the Paintbrush Tuff, 800 to 1,702 feet, bedded tuff from 1,702 to 1,755 feet, and Rhyolite of Calico Hills from 1,755 feet to a depth greater than the bottom of the logged interval. The Topopah Spring Member is densely welded down to the basal vitrophyre; feldspar, trydimite/cristobalite, and quartz are the dominant minerals, with clays generally less than $10 \%$. In the bedded tuffs and Calico Hills units, zeolites are generally the major mineral present and porosity is considerably greater than in the unaltered welded tuffs of the Topopah Spring Member.

Water level was encountered within the bedded tuff at 1,749 feet. We note that this depth is 32.5 feet deeper than the average depth of $1,716.5$ feet recorded by Robison and others (1988) during 1981-1982. The interval below the water level will 
Table 1.--Summary of logs collected in borehole G-2, January 1991

[Where appropriate, AWS model numbers are given in parentheses]

\begin{tabular}{|c|c|c|}
\hline Company & Primary Service & Log traces shown in figures \\
\hline AWS & CAL - six-arm caliper & $\begin{array}{l}\text { AVG - average diameter of } 3 \text { arms } \\
\text { C14 - caliper, arms } 1 \text { and } 4 \\
\text { C25 - caliper, arms } 2 \text { and } 5 \\
\text { C36 - caliper, arms } 3 \text { and } 6\end{array}$ \\
\hline AWS & $\begin{array}{l}\text { DIFL - dual induction } \\
\text { focused log }\end{array}$ & $\begin{array}{l}\text { RILD - deep induction } \\
\text { RILM - medium induction } \\
\text { RFOC - focused resistivity }\end{array}$ \\
\hline AWS & $\begin{array}{l}\text { CDL - compensated } \\
\text { density } \log (2213)\end{array}$ & DENT2 - density \\
\hline AWS & $\begin{array}{l}\text { ZDEN - compensated } \\
\text { z-density log }(2222)\end{array}$ & $\begin{array}{l}\text { ZDEN - density } \\
\text { PE - photoelectric }\end{array}$ \\
\hline AWS & $\begin{array}{l}\text { CDL (DBC) - compensated } \\
\text { density log }(2220) \\
\text { (Birdwell tool) }\end{array}$ & DENT1 - density \\
\hline AWS & $\begin{array}{l}\text { CDL - compensated } \\
\text { density } \log (2227)\end{array}$ & DEN - density \\
\hline AWS & $\begin{array}{l}\text { ENP - epithermal neutron } \\
\text { (2433) (Birdwell tool) }\end{array}$ & NEU - epithermal neutron \\
\hline AWS & $\begin{array}{l}\text { SWN - sidewall neutron } \\
(2415)\end{array}$ & SWN - epithermal neutron \\
\hline AWS & $\begin{array}{l}\mathrm{CN} \text { - compensated neutron } \\
(2420)\end{array}$ & Bad tape, no traces shown \\
\hline AWS & DIEL - dielectric (1531) & $\begin{array}{l}\text { D4EC - dielectric permittivity } \\
\text { R4SL - resistivity }\end{array}$ \\
\hline AWS & $\begin{array}{l}\text { SGR - spectralog (spectral } \\
\text { gamma ray) }\end{array}$ & $\begin{array}{l}\text { K - potassium } \\
U \text { - uranium } \\
\text { TH - thorium } \\
\text { GRKUT - gamma ray }\end{array}$ \\
\hline EDCON & Borehole gravity & GRAV - density over depth intervals \\
\hline SWS & $\begin{array}{l}\text { Phasor - Induction log } \\
\text { (run } 3 \text { times to record at } \\
10,20 \text {, and } 40 \mathrm{kHz} \text { ) }\end{array}$ & $\begin{array}{l}\text { IDPH - deep induction, phasor } \\
\text { IMPH - medium induction, phasor } \\
\text { SFLU - spherically focused resistivity }\end{array}$ \\
\hline sws & $\begin{array}{l}\text { LDTD - Lithodensity; runs made } \\
\text { with and without } \\
\text { neutron source (CNTG) }\end{array}$ & $\begin{array}{l}\text { RHOB - density } \\
\text { PEF - photoelectric }\end{array}$ \\
\hline sws & CNT-G - compensated neutron & $\begin{array}{l}\text { TNPH - thermal neutron, processed } \\
\text { NPHIRV - epithermal neutron porosity, } \\
\text { processed for air-tilled borehole }\end{array}$ \\
\hline SWS & $\begin{array}{l}\text { SNP - sidewall neutron } \\
\text { (epithermal) }\end{array}$ & $\begin{array}{l}\text { SNP - epithermal neutron porosity } \\
\text { CALI - caliper }\end{array}$ \\
\hline SWS & $\begin{array}{l}\text { DPT - deep propagation tool } \\
\text { (resistivity, dielectric not } \\
\text { computed) }\end{array}$ & $\begin{array}{l}\text { DEDP - diclectric permittivity } \\
\text { DRDP - resistivity }\end{array}$ \\
\hline sws & $\begin{array}{l}\text { NGT - natural gamma ray } \\
\text { spectronmetry }\end{array}$ & $\begin{array}{l}\text { THOR - thorium } \\
\text { URAN - uranium } \\
\text { POTA - potassium } \\
\text { SGR - gamma ray, total }\end{array}$ \\
\hline SWS & $\begin{array}{l}\text { TDTP - thermal neutron decay } \\
\text { time }\end{array}$ & TPHl - porosity \\
\hline
\end{tabular}




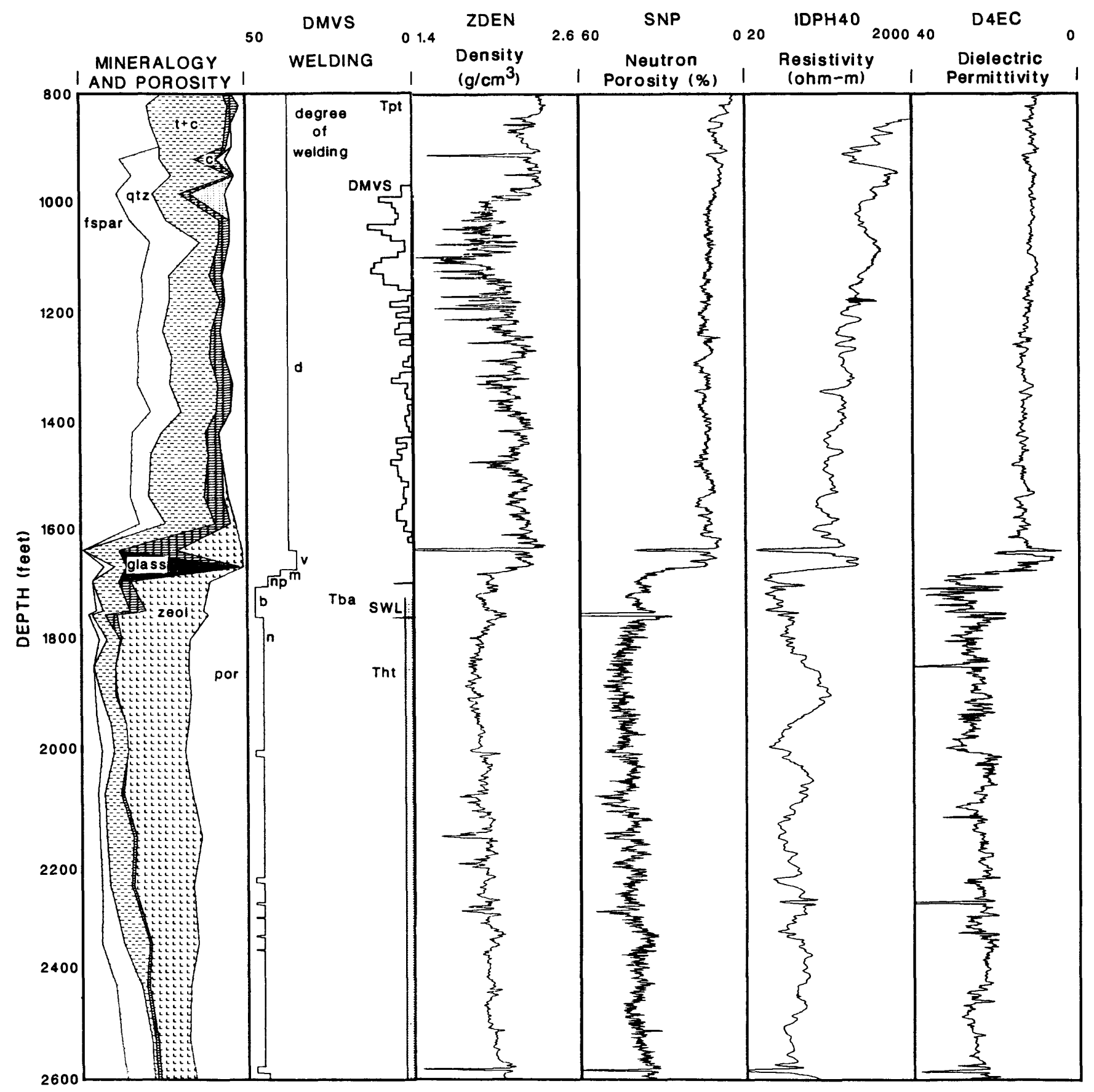

Figure 1.--Geological information and four representative logs (density, epithermal neutron, induction, and dielectric) acquired in January, 1991. Mineralogy taken from Bish and Chipera (1989), degree of welding from Maldonado and Koether (1983), lithophysal void space from Muller and Spengler (1989). Note location of static water level in track 2. Names of logs are explained in table 1. 
be referred to as the saturated zone (SZ) and above, as the unsaturated zone (UZ). The logged interval is satisfactory for assessing $\log$ performance in the UZ, as most of the Topopah Spring Member was logged. However, the sampling of conditions below the water table is not as representative, as none of the units underlying the zeolitized Calico Hills unit were sampled. The dramatic change in physical properties reflected by the shift in the logs at the bottom of the basal vitrophyre (1,680 feet) is caused by the presence of high porosity and zeolites, both of which cause the density to decline, the neutron porosity to increase, resistivity to drop, and dielectric permittivity to increase. (In this report, traces are plotted so that increases in porosity cause traces to deflect to the left).

In the UZ, the character of the density trace reflects the abundance of lithophysae, or voids (DMVS in track 2 of fig. 1). Because the lithophysal zones lie in the UZ, the lithophysae are airfilled rather than water-filled. Bulk density declines where lithophysae are most abundant, and low-density spikes occur wherever the density tool encounters an air gap, whether a void space or an increașe in borehole diameter (borehole washout). The monotonic trends in the neutron, resistivity, and dielectric traces from 1,600 to 800 feet reflect a decrease of total water with elevation above the static water level, and probably a decrease in water saturation.

\section{DISCUSSION OF LOGS}

\section{Caliper Log}

The logged section was drilled with an 8.75inch bit. Wherever the hole is free of breakouts, the AWS six-arm caliper shows a 9-inch hole (see 950 to 970 feet in fig. 2). Most openings recorded by the caliper extend 1 to 2 inches beyond hole size, with two exceptions. At 1,632 feet, the caliper records an opening to 31 inches (fig. 3 ) and at 2,583 feet, an opening to 18 inches (fig. 8). These two openings are so large that they affect the response of most other logs, as seen on many of the figures. Repeatability of the six-arm caliper is satisfactory.

Examination of the six-arm (three-diameter) presentation shows that the hole, even where enlarged, is nearly circular from 800 to 2,050 feet and again from 2,350 to 2,630 feet. A representative section from 950 to 1,100 feet, illustrating near circularity, is shown in the left half of fig. 2. How- ever, the three diameters differ over the interval between 2,050 and 2,350 feet, indicating that the hole is out-of-round by as much as 5 inches (refer to detail at 2,150 feet in fig. 2).

The detail on the AWS six-arm caliper is much better than that on the caliper recorded with any of the density or neutron logs which employ a skidmounted sensor pad. This is as expected because a skid-mounted caliper cannot have the resolution of an arm with a tip. We did note that the proximity caliper log (not shown in figures) carried on one of the AWS neutron tools does display higher spatial resolution than the six-arm caliper. However, the total displacement of the proximity caliper is limited and it is not a true caliper because it measures opening from the skid rather than across the borehale.

\section{Density Logs}

All five density tools produce logs which replicate one another fairly well and which capture the gross declines in density in the lithophysal zones (fig. 3). Repeatability of individual features at the scale of 10 feet and less appears quite good in the SZ (fig. 4) and adequate in the UZ (fig. 6). Variations in features and in character among the tools can be seen by scanning figs. 3-6. Occasionally, in the UZ, a log shows a low density peak where none of the other logs do; such differences can be attributed to the tools travelling along different sectors of a rough borehole wall. The AWS tools resemble one another in terms of spatial frequency content more than they resemble the SWS trace; this difference is attributed to differences in filter characteristics.

Absolute values of density differ among the tools: the average values tabulated in table 2 , over relatively quiet 100 -foot intervals, quantify the offsets of the five tools. The AWS 2213 and 2220 tools read considerably lower than the other four; averages from the 2227, ZDEN, RHOB, and DBC (1981) traces read within $0.035 \mathrm{~g} / \mathrm{cm}^{3}$ of each other (bottom four lines of table 2).

Density values from the older AWS tool, the 2213, are considerably less than from the other four tools. In particular, the density measured by the 2213 (DENT2 in fig. 4) shifts markedly at the airwater interface at 1,750 feet. The 2213 is smaller than the other density tools (roughly 3 inches versus 4.5 inches) as it was designed to operate in small diameter holes. The tool should not be used in holes larger than 6 inches diameter, and it does not 

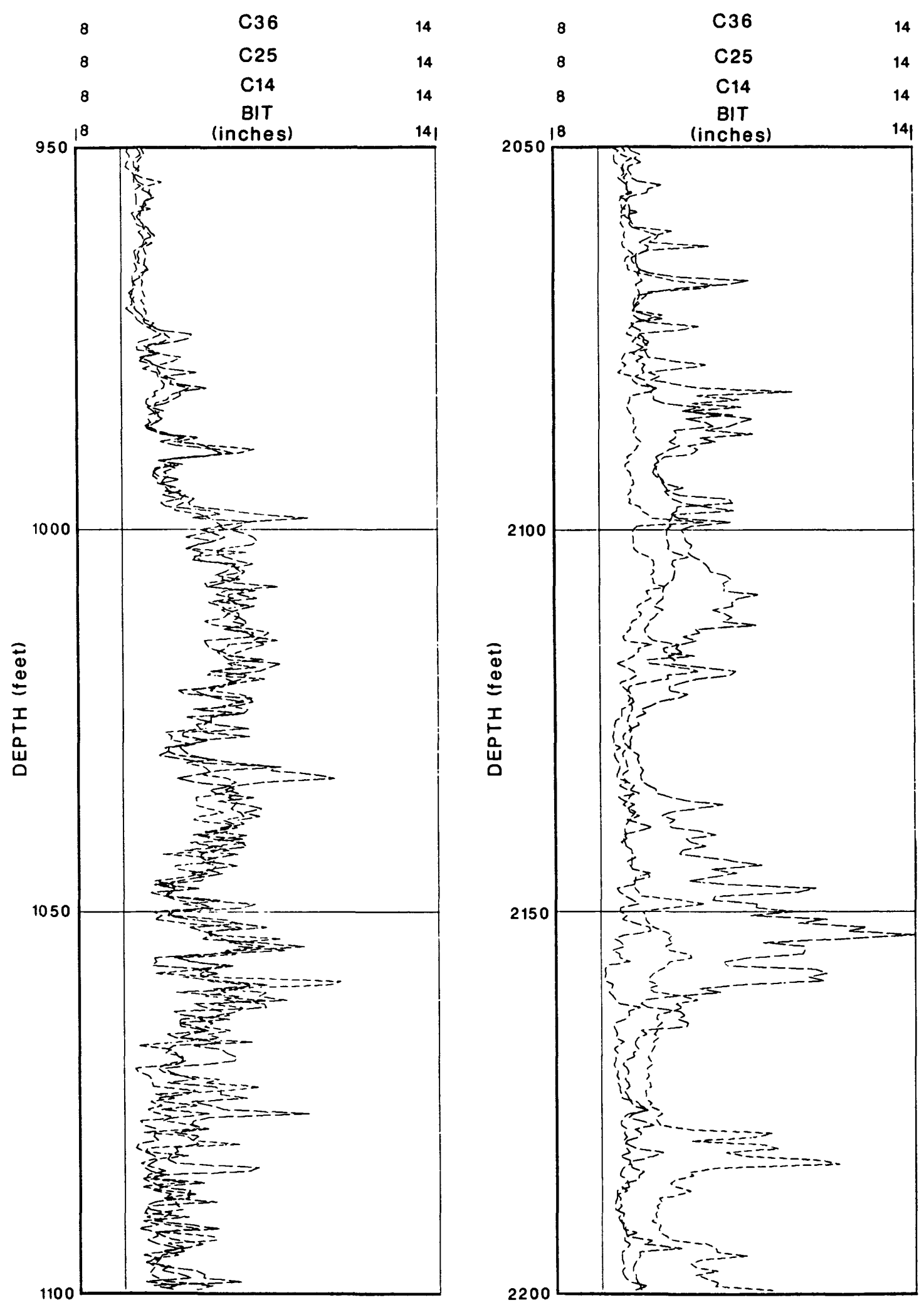

Figure 2.--Two detailed sections of the AWS six-arm caliper log from the unsaturated zone (left) and saturated zone (right). Bit size, shown by vertical line, is 8.75 inches. Each trace--C14, C25, and C36--corresponds to one of three pairs of arms, set 120 degrees apart. 


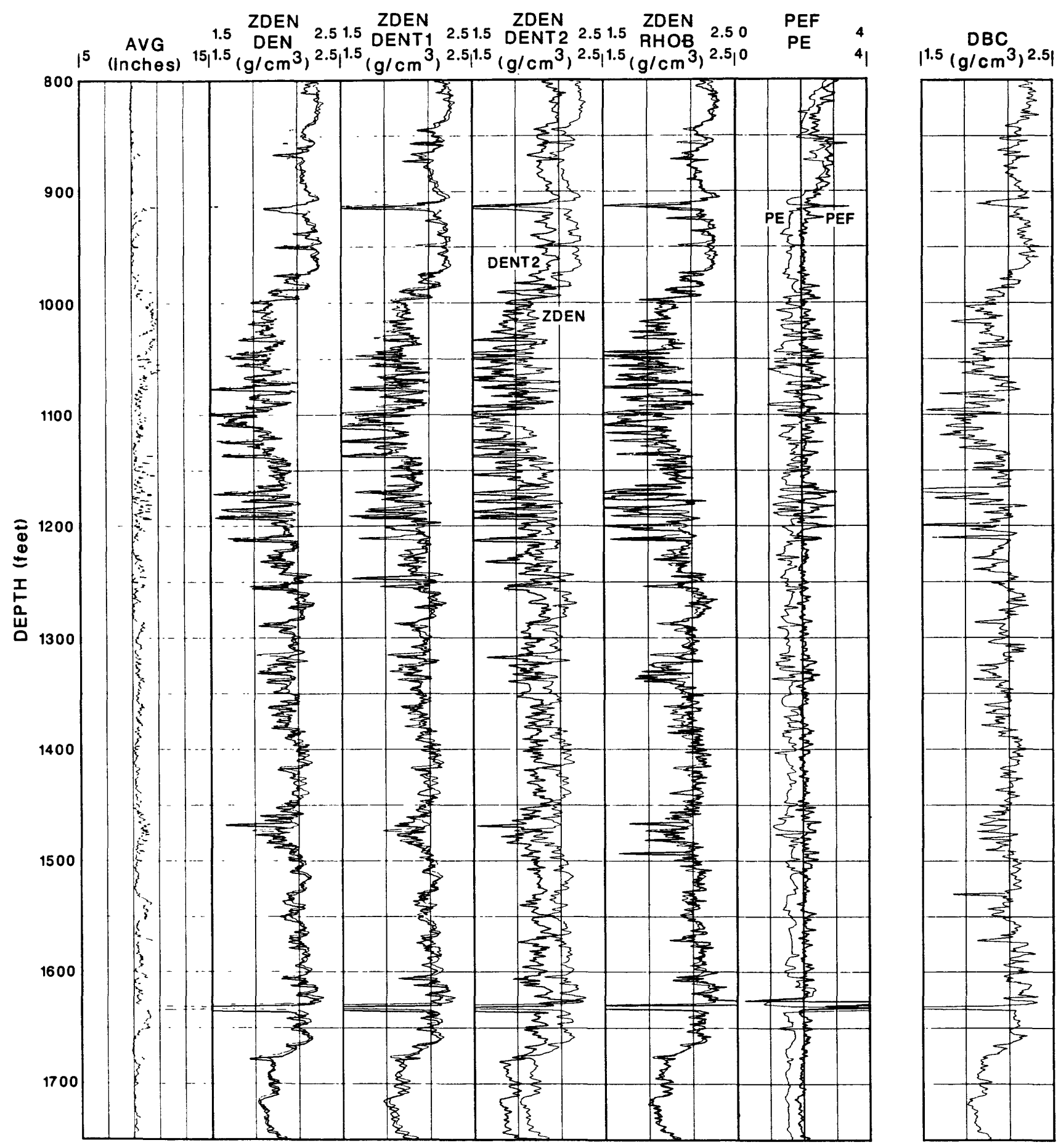

Figure 3.--Caliper (AVG), five density logs, and two photoelectric logs in the unsaturated zone. See table 1 for explanation of trace names. The density trace "ZDEN" is shown four times for comparison purposes. Also, the Birdwell log "DBC" from 1981 is shown at extreme right. 


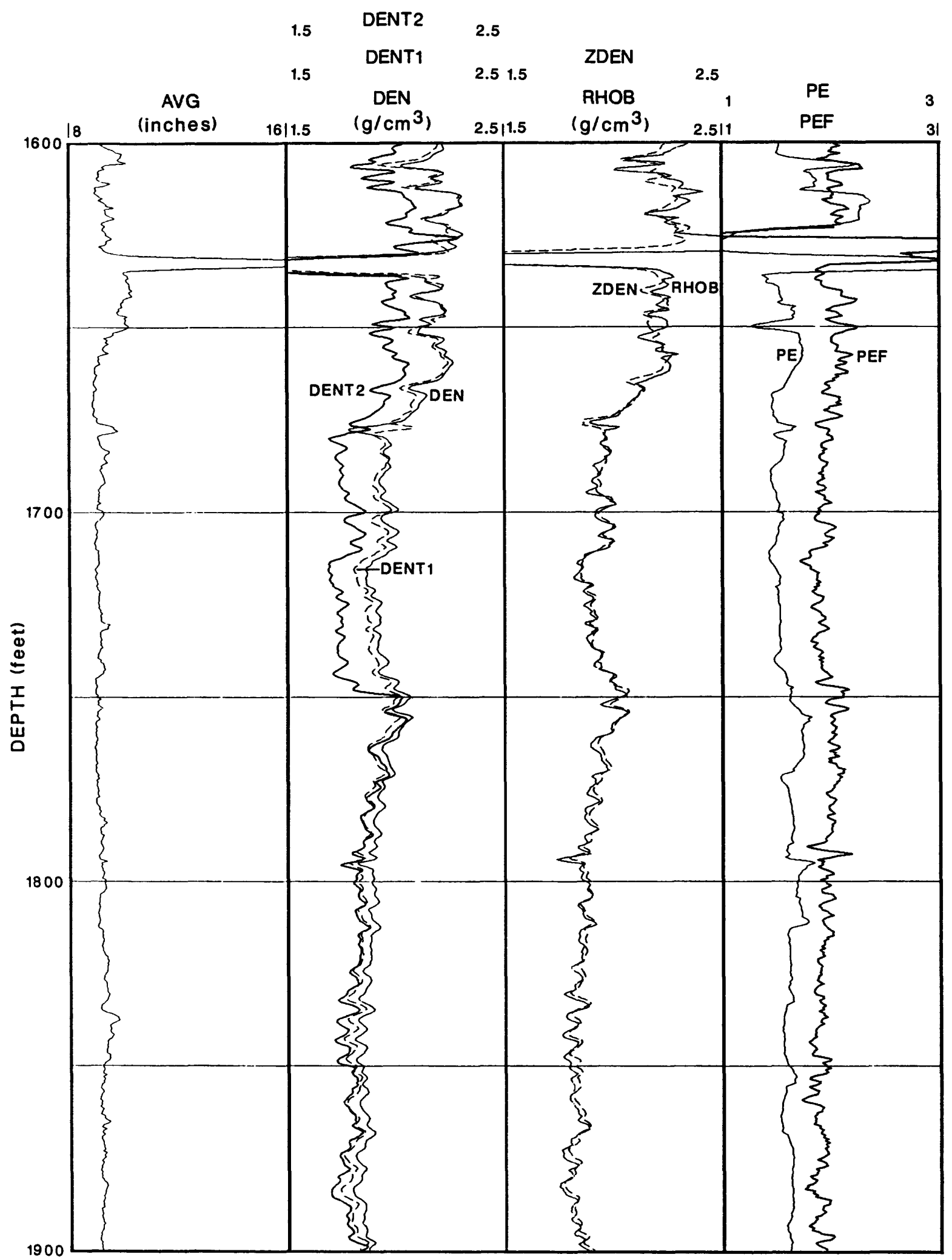

Figure 4.--Expanded view of caliper, five density logs, and two photoelectric logs across the boundary at 1,750 feet between the saturated and unsaturated zones. 


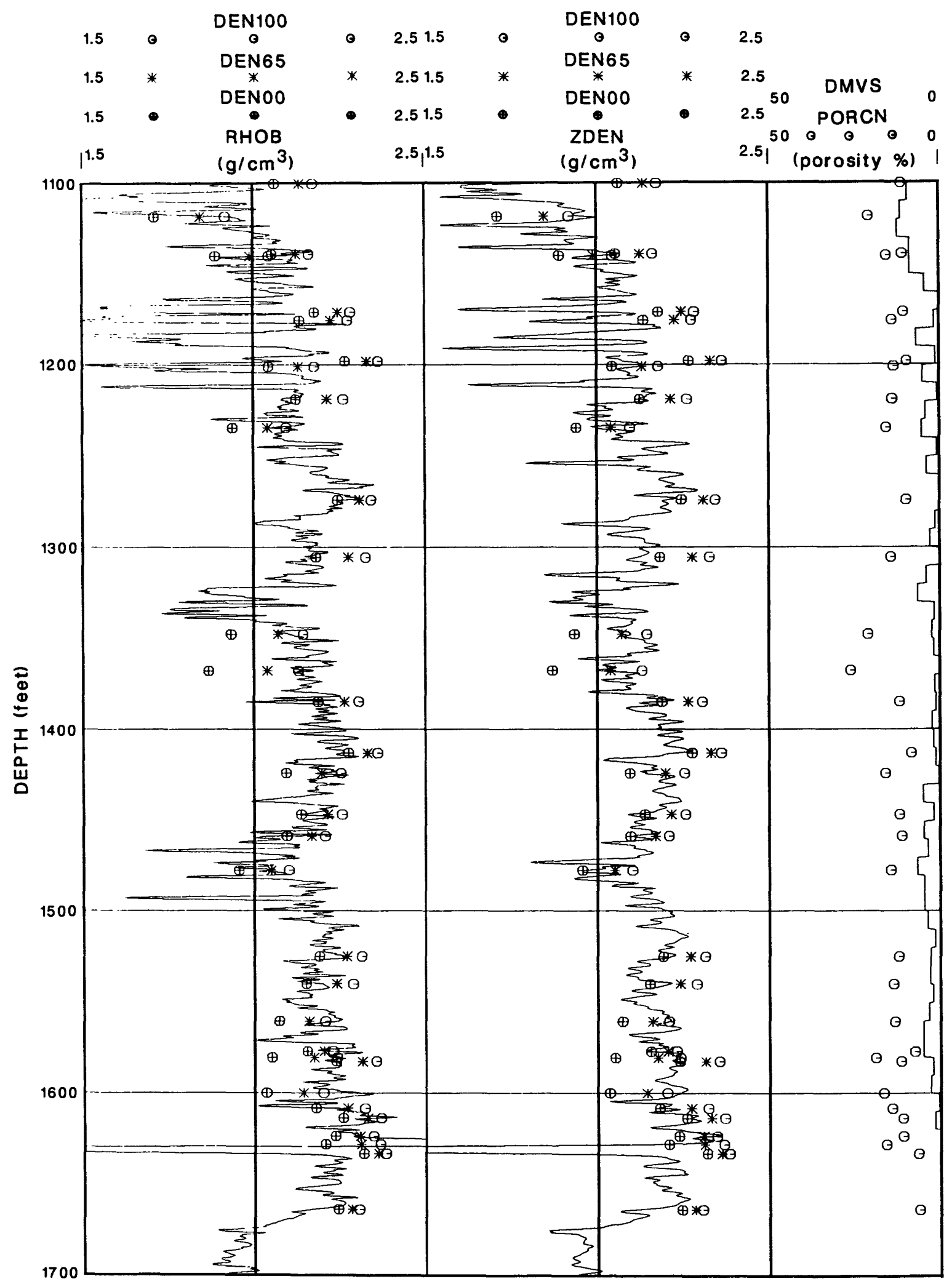

Figure 5.--SWS (RHOB) and AWS (ZDEN) density logs shown with densities computed from core data. Void space (DMVS) and core porosity (PORCN) were used to compute the unsaturated density DENOO. Pore space saturations of 65 percent and 100 percent yield densities labeled DEN65 and DEN100. 


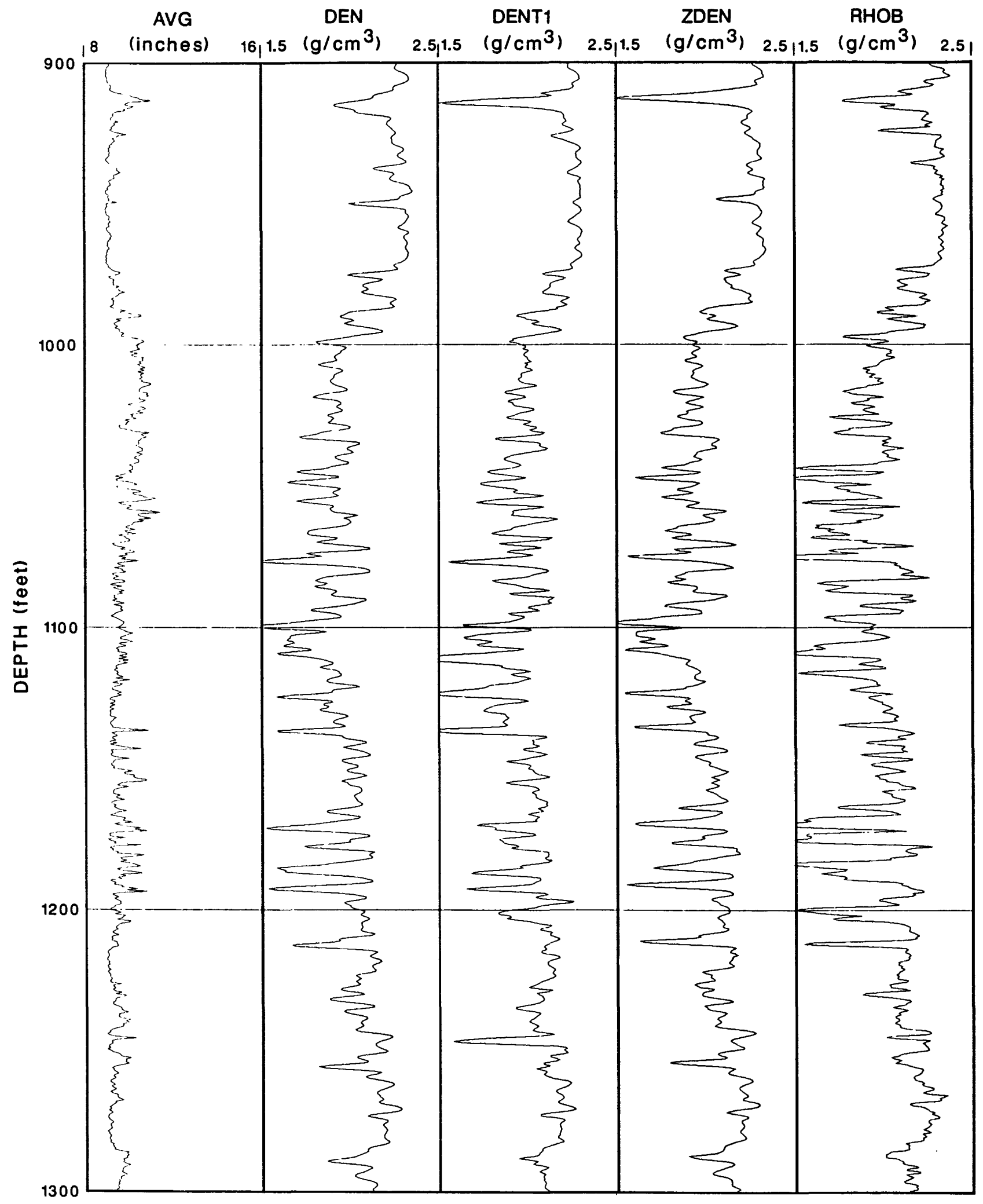

Figure 6.--Four density logs over the interval 900 to 1,300 feet. The interval 1,000 to 1,200 feet corresponds to the high-lithophysal zone (see fig. 1). 
Table 2.-Average density and standard deviation $\left(\mathrm{g} / \mathrm{cm}^{3}\right)$ over four depth intervals (feet) for six density tools

\begin{tabular}{|l|l|c|c|c|c|}
\hline $\begin{array}{c}\text { Company } \\
\text { and model }\end{array}$ & \multicolumn{1}{|c|}{$\begin{array}{c}\text { Trace } \\
\text { name }\end{array}$} & $\mathbf{8 0 0 - 9 0 0}$ & $\mathbf{1 , 5 0 0 - 1 , 6 0 0}$ & $\mathbf{1 , 8 0 0 - 1 , 9 0 0}$ & $\mathbf{2 , 4 7 5 - 2 , 5 7 5}$ \\
\hline AWS & DENT2 & 2.078 & 1.989 & 1.787 & 1.940 \\
2213 & 0.059 & 0.052 & 0.040 & 0.047 \\
\hline AWS & DENT1 & 2.223 & 2.153 & 1.812 & 1.942 \\
\hline AWS & & 0.076 & 0.047 & 0.030 & 0.039 \\
\hline 2227 & DEN & 2.247 & 2.162 & 1.858 & 0.988 \\
\hline AWS & & 0.058 & 0.054 & 0.028 & 0.039 \\
\hline 2222 & ZDEN & 2.249 & 2.183 & 1.843 & 1.981 \\
\hline SWS & & 0.072 & 0.048 & 0.031 & 0.039 \\
LDTD & RHOB & 2.257 & 2.197 & 1.824 & 1.969 \\
\hline Birdwell & DBC & 0.070 & 0.056 & 0.036 & 0.042 \\
\hline$(1981)$ & & 2.251 & 2.179 & 1.831 & 1.966 \\
\hline
\end{tabular}

perform well in air, a deficiency attributed to its smaller pad size and consequently, less shielding on the sides and back of the detectors (B. Mountjoy, AWS, oral commun., 1992).

Measurements of density on core samples from G-2 were reported by Nimick and Schwartz (1987). Their measurements were restricted to the Topopah Spring Member of the Paintbrush Tuff; they did not obtain measurements below the static water level. Dry bulk density was determined by drying and weighing, grain density was determined by pycnometry, and porosity was computed from the dry bulk and grain densities. It is, of course, desirable to compare the density logs directly with core measurements, but the unknown and variable state of saturation in the UZ makes the comparison unreliable as a means of determining the accuracy of the logs. The lithophysae present another complication; lithophysae will in general be sampled by the logs but are unrepresented or underrepresented in small core samples.

We have taken the following steps to account for the difficulties presented by partial saturation and lithophysae. The equation for the density $\rho$ of a partially saturated sample is,

$$
\rho=\rho_{g}\left(1-\phi_{m}-\phi_{v}\right)+\rho_{w} \phi_{m} S_{w}
$$

The grain density $\rho_{g}$ and matrix porosity $\phi_{m}$ values determined by Nimick and Schwartz (1987) have been combined with estimates of void space $\phi_{v}$ presented by Muller and Spengler (1989). Setting $\rho_{w}=1.0$, three density values are then computed at zero saturation $\left(\rho_{0}\right)$, partial saturation $\left(\rho_{65}\right)$, and full saturation $\left(\rho_{100}\right)$ corresponding to $S_{w}=0,0.65$, and 1.0 ,

$$
\begin{aligned}
& \rho_{\mathrm{o}}=\rho_{\mathrm{g}}\left(1-\phi_{\mathrm{m}}-\phi_{\mathrm{v}}\right) \\
& \rho_{65}=\rho_{\mathrm{o}}+0.65 \phi_{\mathrm{m}} \\
& \rho_{100}=\rho_{\mathrm{o}}+1.0 \phi_{\mathrm{m}} .
\end{aligned}
$$

A saturation of 0.65 was chosen to represent the average saturation of the Topopah Spring Member, as given in table 1 of Montazer and Wilson (1984). Note that both matrix pore space and void space, which combine to form total porosity, are used to compute the dry bulk density, but that only matrix pore space is used to add the contribution of saturated or partially saturated pore space. In doing so, we have assumed that the void space is always unsaturated. The void space ( $\left.\phi_{\mathrm{v}}=\mathrm{dmvs}\right)$ and pore space $\left(\phi_{m}=\right.$ porcn $)$ data are shown in the righthand column of fig. 5 .

If all measurements were done accurately, we would expect the logs in fig. 5 to fall between $\rho_{0}$ and $\rho_{100}$, tending to cluster around $\rho_{65}$. In general this is true for both the AWS and SWS logs, although in both cases some samples are not intersected by the logs at all. Of course, the comparison is marred by the usual uncertainties of depth matching and 
matching and sample size that one encounters in comparing logs and core data, here compounded by the errors inherent in estimating the void space. Examining the interval from 1,400 to 1,600 feet in detail, it appears that the agreement between sample values and $\log$ values is occasionally better for the SWS $\log$ than for the AWS log. It appears that the higher spatial frequency of the SWS log is revealing more of the detail of real density variations.

The differences in character between the SWS (RHOB) and AWS (ZDEN) logs are further illustrated in fig. 6 , including the interval 1,000 to 1,200 feet which contains the highest void (lithophysal) space, and hence the lowest density values within the Topopah Spring Member. The sharper resolution of the RHOB trace is clearly seen, but one can also see that, where the RHOB trace is affected by voids or borehole washout, the declines in density are sharper and greater than on the AWS traces. Thus, the advantage of increased spatial resolution seems to be offset by loss of data in rough hole or lithophysal zones. It is likely that the AWS tool also loses data in the same locations, but the losses are disguised by smoothing.

In the right-hand track of fig. 7, the difference between RHOB and ZDEN has been plotted as RHOZDF. It is obvious that differences between these two tools are rather extreme in the unsaturated zone between 800 and 1,749 feet. Depth offset appears to be a very minor contributor to the difference. This is most likely due to the fact that neither commercial contractor has a viable correction algorithm for the dry portion of the borehole. Below the water table ( 1,749 feet), trace RHOZDF shows general agreement between the two contractors, except for those sections of the borehole corresponding to large deviations in the diameter of the borehole as shown on trace CALI in track 1 . This again is the result of the unrealistically low density spikes on trace RHOB.

We note that the RHOB and ZDEN logs present different estimates of density (tables 2 and 3 ). Below the water table, ZDEN exceeds RHOB by 0.019 and $0.012 \mathrm{gm} / \mathrm{cm}^{3}$; above the water table, RHOB exceeds ZDEN by 0.008 and $0.014 \mathrm{gm} / \mathrm{cm}^{3}$. For the entire section of borehole below the water table (1,750-2,600 feet) this discrepancy averages 0.024 , or 1.892 for RHOB and 1.916 for ZDEN. These differences exceed the standard deviations of the measurements; the core data do not resolve the discrepancy. An error in density of $0.02 \mathrm{gm} / \mathrm{cm}^{3}$ corresponds to an error in porosity of about 0.01 , so it is desirable to reduce absolute errors to 0.01 $\mathrm{gm} / \mathrm{cm}^{3}$.

\section{Methods of Reducing Rugosity Effect}

Density tools are quite susceptible to error in rugose boreholes, and the lack of fluid in the hole worsens the situation (Nelson, Muller, and others, 1991). Here we briefly discuss three concepts that may be useful in treating density logs in the future.

The most fundamental improvement can be made by reducing rugosity created during drilling. Reduction of drilling or reaming speed, or consideration of bit design may reduce rugosity.

Recent results by Flaum and others (1991) show that it is possible to reduce or eliminate the effect of rugosity in mud-filled holes having rugosity on the order of one-half inch. They employ a deconvolution technique utilizing both the near and far detector. The spatial response of the detectors must be known and transformed to the frequency domain. They divide the spatial response into a shallow and deep contribution and devise a way of cancelling the shallow contribution, which contains the rugosity effect. Their laboratory and field examples are convincing evidence that the technique works in low rugosity, mud-filled holes. A field test would be required to determine if the technique can be applied in air-filled holes. The authors emphasize that use of the technique requires high spatial sampling and good statistics. They recommend a sampling density of 0.10 to 0.12 inches and a logging speed of $900 \mathrm{feet} /$ hour (15 feet/minute).

Where the hole is preferentially more rugose at some azimuths than at others (see caliper of fig. 2), the density $\log$ can be greatly improved if the tool is mounted with a special mechanical system ("shortaxis eccentralizer") so that it is forced to ride against the smoother portion of the wellbore. Ellis (1990) presents an example where this was done. The log obtained using the normal procedure resulted in numerous low-density dropouts, whereas the log acquired with the short-axis eccentralizer gave normal density values. The six-arm caliper is useful in assessing this technique for Yucca Mountain boreholes. From inspection of fig 2, it appears that no improvement would have been obtained in the lithophysal portion of G-2, where the hole is rugose but roughly circular, although there might be improvement in the water-filled portion of the hole. Findings from other holes are discussed by Nelson, Muller, and others (1991; p. 16 and fig. 3). They report that eccentric zones, where the long axis is greater than the short axis by 1 to 2 inches, appear to constitute about 5 to 20 percent of hole length. Thus, the evidence indicates that there would not be a very significant improvement by using a short- 


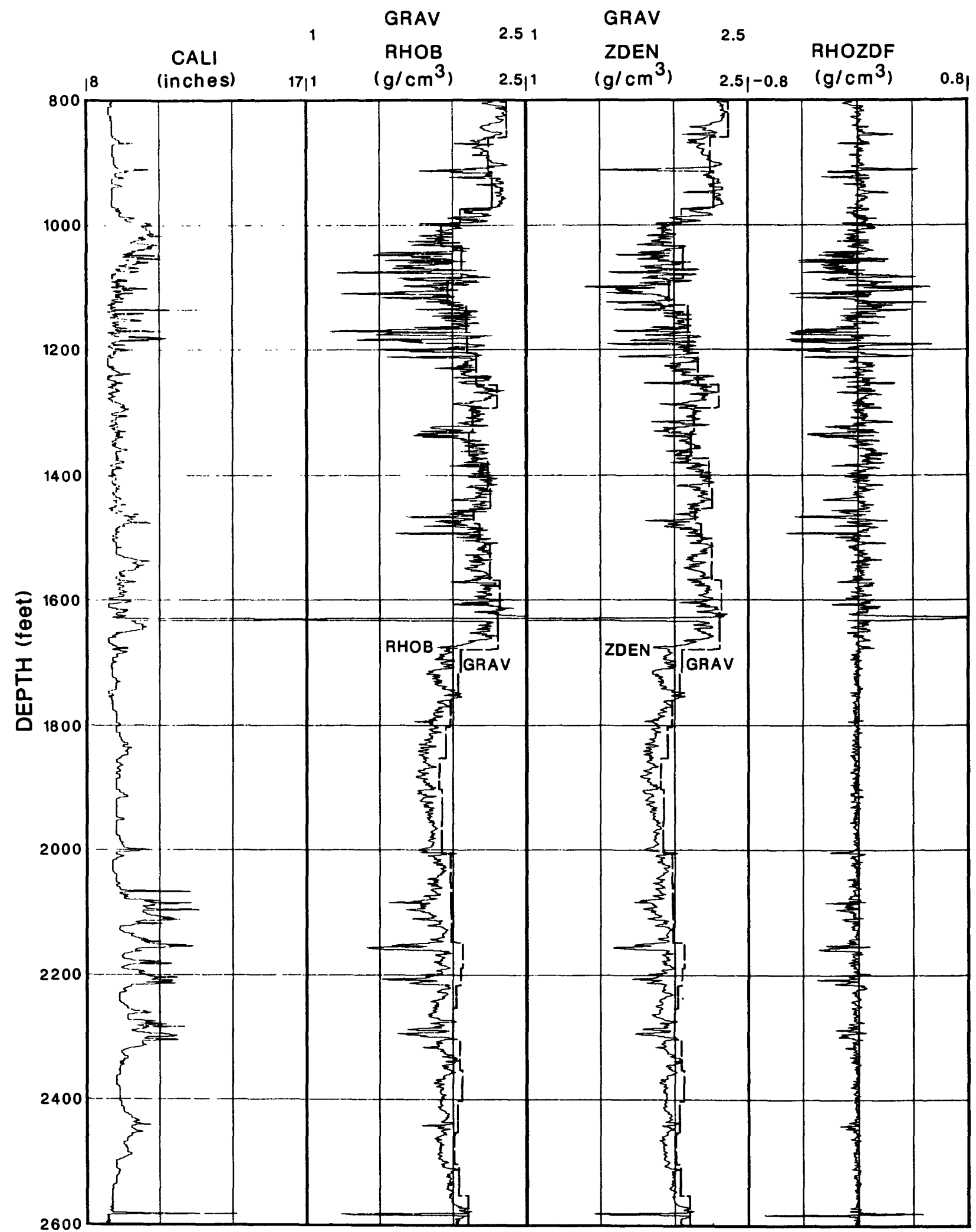

Figure 7.--Density derived from borehole gravimeter (GRAV) run by Edcon, compared with gamma-gamma logs by SWS (RHOB) and by AWS (ZDEN). The trace labeled RHOZDF is RHOB minus ZDEN. Caliper log CALI is in track 1. 
axis eccentralizer in Yucca Mountain boreholes, although the technique could be tried if eccentricity persists or worsens in future drilling.

Table 3.-Mean and standard deviation $\left(\mathrm{g} / \mathrm{cm}^{3}\right)$ over the depth interval 1,750 2,000 feet (water-filled borehole)

\begin{tabular}{|l|l|l|}
\hline \multicolumn{1}{|c|}{ Trace } & \multicolumn{1}{|c|}{ Mean } & \multicolumn{1}{|c|}{$\begin{array}{l}\text { Standard } \\
\text { deviation }\end{array}$} \\
\hline \hline GRAV & 1.938 & 0.029 \\
\hline ZDEN & 1.867 & 0.050 \\
\hline RHOB & 1.848 & 0.053 \\
\hline
\end{tabular}

\section{Photoelectric Logs}

The two photoelectric (PE and PEF in figs. 3 and 4) traces differ in magnitude and in character, although the difference in character (fig. 4) would not look so severe if the logs were depth shifted. The photoelectric log has not been run before at Yucca Mountain. Lacking prior experience with the measurement, we have no assessment at this time as to its utility.

\section{Gravimeter Log}

A borehole gravimeter log was run by Edcon (1991). Readings were obtained at 57 stations in the hole; density values calculated by Edcon from the gravity readings are shown in fig. 7 . Edcon (1991) reports that "the gravity data have been corrected for solar and lunar tides, instrument drift and depth corrections. Densities were calculated for each interval using the true vertical depth measurements and the terrain-corrected gravity values. A terrain density of $1.875 \mathrm{~g} / \mathrm{cc}$ was used for these results." They also report that an attempt to measure the free air gradient was unsuccessful due to wind noise.

The advantage of gravimeter data is that readings are virtually unaffected by borehole rugosity. The tool averages over a volume far greater than that measured by the gamma-gamma density probe; therefore local variations in lithophysal porosity are effectively averaged out. Of course, the disadvantage is that the density values obtained are averages over the vertical interval between station spacings, which, in the case of G-2, was typically 50 feet.
The density resulting from the downhole gravimeter tool is much higher than either of the gamma-gamma density tools (fig. 7). However, in a water-filled borehole of minimal rugosity, the densities from the borehole gravity meter are expected to be identical to the gamma-gamma density values. In a paper discussing these discrepancies at Yucca Mountain, Muller and Spengler (1989) apply a bootstrap approach to correct the gravimeter log. They first compared gamma-gamma density values to core-based density values in the water-filled boreholes and found that agreement was very good. Having established the validity of the gammagamma density log in water-filled boreholes, they then corrected the gravimeter-based density log to match the gamma-gamma density log by adjusting the free-air gradient. We cannot follow their procedure here, because there are no core-based density values for the water-filled portion of borehole USW-G2.

However, based upon our experience with other boreholes at Yucca Mountain, we feel confident that the gamma-gamma density logs are closer to core-based densities in the water-filled borehole than are the gravimeter-based densities. Examining fig. 7 , a suitable section for quantitative comparison of the gravimeter and gamma-gamma density logs can be seen between the depths of 1,750-2,000 feet. Averages over these intervals are given in table 3.

To match trace ZDEN for this depth interval of $1,750-2,000$ feet, a value of $0.071 \mathrm{~g} / \mathrm{cm}^{3}$ must be subtracted from trace GRAV. To match trace RHOB, a value of $0.090 \mathrm{~g} / \mathrm{cm}^{3}$ must be subtracted from trace GRAV. Of course there is a discrepancy of $0.02 \mathrm{~g} / \mathrm{cm}^{3}$ between ZDEN and RHOB, an issue discussed in the preceding section. The point here is that density derived from the gravimeter log requires adjustment for a poorly known free-air gradient. Once adjusted, it is clear that the gravimeter log provides density values which conform quite well to the density logs. Most importantly, in the air-filled borehole, the gravimeter provides density values which form a right-hand "edge" to the erratic density logs obtained from the gamma-gamma tools

\section{Neutron Logs}

Three types of neutron logs were run: two compensated thermal neutron and one compensated epithermal log, three sidewall epithermal neutron logs, and one decay time (die-away) log. All tools functioned below the water table (fig. 8) but only the epithermal tools worked in the air-filled portion 


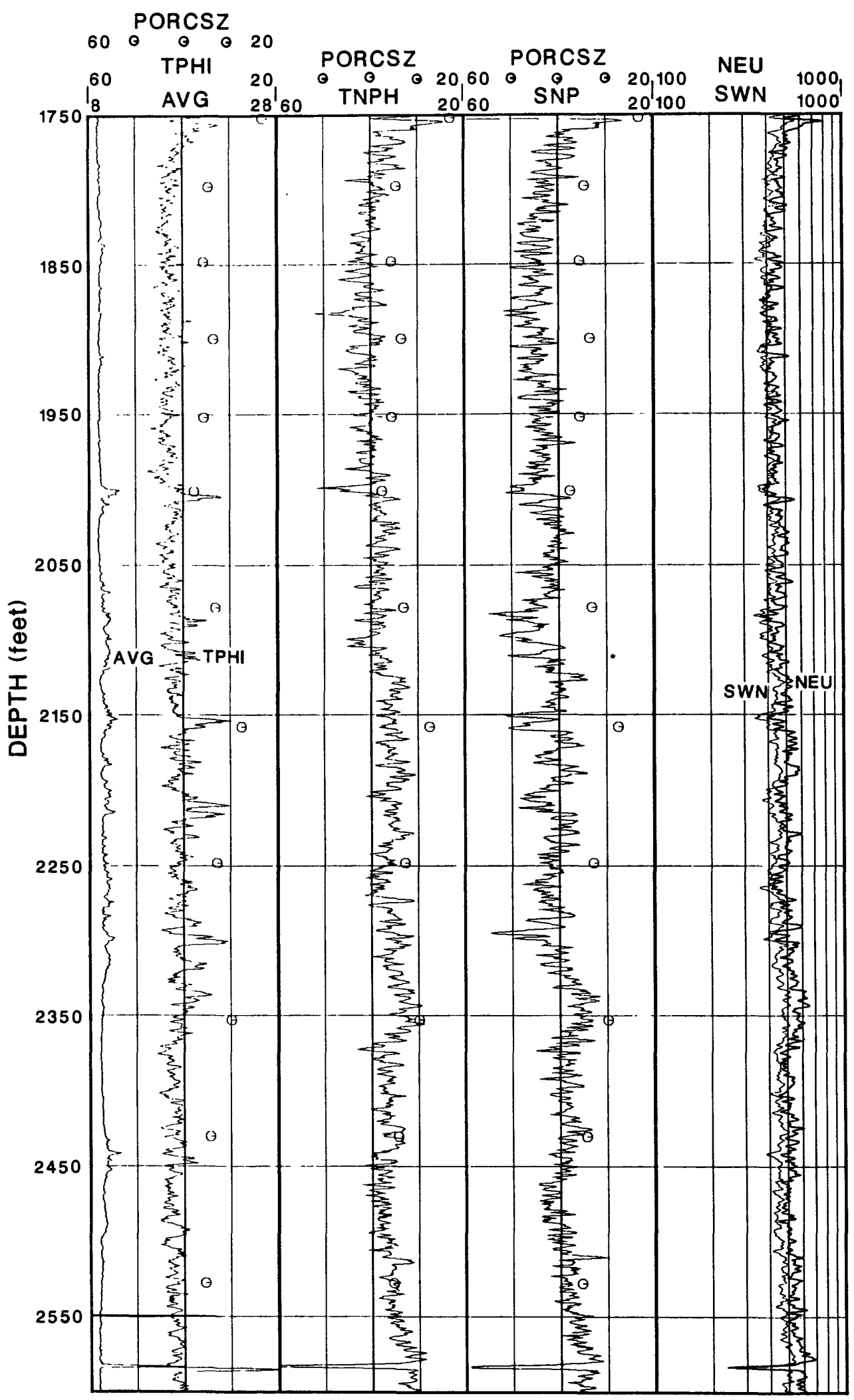

Figure 8.--Neutron and caliper (AVG) logs from the saturated zone. First two tracks show thermal neutron logs TPHI and TNPH; third track shows epithermal SNP log on a porosity scale; fourth track shows two epithermal neutron (NEU and SWN) logs on logarithmic API scale. Point porosity estimates PORCSZ are included in first three tracks. 


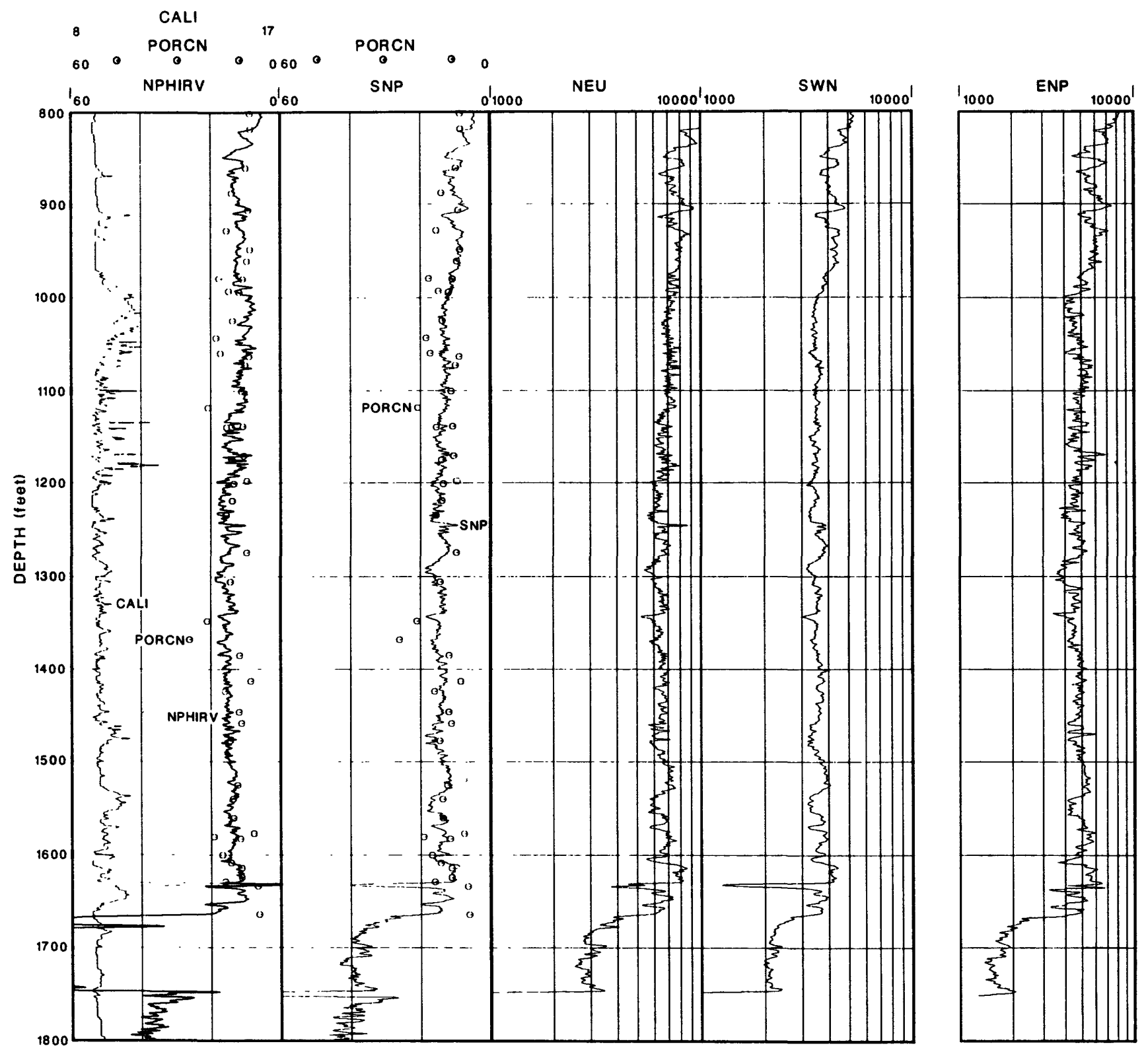

Figure 9.--Epithermal neutron and caliper logs from the unsaturated zone. The NPHIRN log in track 1 is from the epithermal detectors on the SWS' CNT-G tool. The SNP log by SWS is on a porosity scale. Logarithmic API scales are used for the NEU and SWN logs by AWS and the ENP log by Birdwell run in 1981. Porosity measurements on core samples (tracks 1 and 2) are from Nimick and Schwartz (1987). 
Table 4.-Neutron logs run in water-filled borehole $(1,750-2,650$ feet) In zeolltic tuff ["pu" designates porosity units or percent porosity]

\begin{tabular}{|l|l|l|l|}
\hline Company \& tool & \multicolumn{1}{|c|}{ Description } & \multicolumn{1}{c|}{$\begin{array}{c}\text { Range } \\
1,800-2,630 \text { feet }\end{array}$} & \multicolumn{1}{|c|}{ Repeat checks } \\
\hline \hline AWS 2420XA & Compensated thermal & $21-30 \mathrm{pu}$ & No repeatability \\
\hline SWS CNT-G (nphi) & Compensated thermal & $30-42 \mathrm{pu}$ & Some \\
\hline SWS CNT-G (enph) & $\begin{array}{l}\text { Compensated } \\
\text { epithermal }\end{array}$ & $33-51 \mathrm{pu}$ & No repeatability \\
\hline AWS 2415 & Sidewall epithermal & $400-500 \mathrm{api}$ & Inadequate resolution \\
\hline AWS 2433 & Sidewall epithermal & $500-550 \mathrm{api}$ & Inadequate resolution \\
\hline SWS SNP & Sidewall epithermal & $33-48 \mathrm{pu}$ & No repeatability \\
\hline SWS TDTP & $\begin{array}{l}\text { Thermal neutron } \\
\text { decay time }\end{array}$ & $34-43 \mathrm{pu}$ & Fair \\
\hline
\end{tabular}

of the borehole (fig. 9). This was no surprise, as the long-spaced thermal neutron tools have never provided valid data in air-filled boreholes

\section{Response In the zeolitic zone}

The repeat runs were all run in the water-filled borehole in the zeolitized zone, where hydrogen is present both structurally and adsorbed in zeolites, as well as in water in pore space. Because the total hydrogen (water) content is so high in the zeolitic zone, the neutron count rates are quite low from both thermal and epithermal tools. Consequently, the repeatability was very poor for all tools (table 4); it would be better to say that repeatability was non-existent at the scale of 5 to 10 feet when examining porosity variations on the order of 2 to 4 percent of pore space. In other words, the detailed character within the zeolitic zone is completely inadequate and cannot be reproduced from run to run with the same tool. Nor, of course, can the detailed character be duplicated by different neutron tools (fig. 8).

Overall accuracy also suffers in the zeolitic zone; the different tools yield different porosity estimates (table 4, fig. 8). Porosity values from core data were not available, so point values of porosity were computed from the 1981 density log and grain density estimates from mineralogy by Bish and Chipera (1989). These point porosity estimates are shown as open circles in fig. 8. Because of the extra hydrogen present in the zeolites, we expect the neutron porosity logs to exceed the point porosity values. This is the case for all three neutron logs shown on a porosity scale (TPHI, TNPH, SNP) in fig. 8, which are generally higher than the point values. The gradual decrease in zeolite minerals with depth shown in fig. 1 is reflected in fig. 8 in the gradual decrease in the difference between the TNPH and SNP neutron logs and the point porosity estimates. In this regard, of the three porosity estimates from neutron logs, the SNP appears the most realistic.

Two neutron logs were presented erroneously on tape and so are not shown here. The epithermal trace (enph) from SWS' CNT-G tool was similar in character to TNPH on the paper print. Nor could the AWS compensated thermal neutron tool (model 2420 ) be read from tape. As shown in table 4, the neutron porosity values from the 2420 in the zeolitic tuffs are considerably lower than those recorded by the other tools. According to AWS personnel, the model 2420 tool does tend to read low in shales having high apparent porosity. Because the tool has been discontinued and because the AWS 2435 , although not run, is now the preferred AWS thermal neutron tool, there will be no further discussion of the 2420 . 
Epithermal neutron logs in the unsaturated zone

All three sidewall epithermal logs--AWS 2415, AWS 2433, and SWS SNP--show the same features in the unsaturated zone (fig. 9). Despite the different scales used (API vs. porosity), it is apparent that all three tools are responding similarly, as is the 1981Birdwell log (although it is considerably noisier). Of the three logs run in 1991, the AWS 2433 appears noisier than either the AWS 2415 or the SWS SNP. It is dangerous to make comparisons regarding noise content without understanding the filtering applied to the data. Because the AWS logs were not converted from API units to porosity, they cannot be compared quantitatively with the SNP porosity log. However, the two AWS logs differ by a factor of two in API units (fig. 9)! So there is a clear problem in referencing the AWS tools to the API standard.

Conversion to water-filled porosity for both air-filled and water-filled holes was applied to the SNP log run by SWS. Comparison with the corebased porosity values (porcn) shows an impressive agreement (fig. 9); however, in the partially saturated rock of the UZ, the SNP log should read less than total core porosity. An explanation lies in the presence of clays throughout the UZ (fig. 1); hydrogen content of clay increases the SNP response. Thus, although the apparent agreement is satisfying, it is somewhat fortuitous.

Porosity also was calculated from the epithermal detectors on the mandrel-type tool referred to by SWS as the CNT-G (see trace "NPHIRV" in fig. 9). The algorithm for this tool is described by Galford and others (1991); recovery of porosity data in air-filled holes with this tool was first described by Flaum (1983). According to Flaum, neutron moderation in a water-filled borehole means that the neutron source can be regarded as a point source. In an air-filled borehole, no such moderation exists and the neutron source must be regarded as distributed along the borehole. As a result of this phenomenon, sometimes referred to as "neutron streaming," the response of a two-detector tool is quite different in an air-filled hole than in one filled with water. The methods developed by Galford and others (1991) are specific to air-filled boreholes.

Inspection of trace NPHIRV in fig. 9 reveals that, on the positive side, the porosity levels are comparable to the sidewall epithermal logs and to the core porosity. However, there are two problems. The algorithm failed to yield results in the very high $(>30 \%)$ porosity from $1660-1750$ feet; at very high porosities the epithermal count ratio is relatively insensitive to porosity changes; Galford and others (1991) acknowledge these inadequacies in the algorithm. A second problem is reflected by significant differences in curve character. For example, the NPHIRV trace shows a decrease in porosity from 990-1,060 feet with respect to the three sidewall traces. This difference is attributed to the hole size correction applied to the NPHIRV trace (note caliper opening from 9 to 10.5 inches). W. Nagel (written commun., 1992) has pointed out that, at $10 \%$ porosity, a hole size increase from 8 to 9 inches requires a correction of $7 \%$ porosity, an an increase from 8 to 10 inches requires a corrrection of $16 \%$ porosity! Thus the correction is of the same magnitude as the measurement, and small errors in the caliper log will produce significant errors in porosity. The hole-size adjustment increases linearly with porosity, and so is much more important for the UZ where porosity ranges from 10 to $20 \%$, than for the examples cited by Galford and others (1991), where porosity is generally less than $10 \%$. From these points, it is apparent that computation of porosity from the CNT-G epithermal tool is not adequate and should not be pursued further.

\section{Thermal decay time log}

The TDT did not function in the air-filled hole, so not much was gained from the TDT run. SAIC (1991a, p. 19) states that the TDT requires a boron sleeve to operate in an air-filled hole but that the sleeve was not present at the site. They also state that the minitron source was too high for this borehole size in air. This failure to obtain data was disappointing because apparently some investigators have had success using the TDT in gas-filled cased boreholes (Butsch and Vacca, 1990).

Within the water-filled borehole, response from the TDT tool is remarkably uniform. Sigma values range from 15 to 15.5 and porosity (tphi in fig. 8 ) is around 42 percent, consistently higher than the point values of porosity.

\section{Spectral gamma-ray logs}

Spectral gamma-ray logs were obtained by AWS (model 1318) and by Schlumberger (NGT) yielding estimates of potassium, uranium, and thorium. The AWS tool uses a 2-inch o.d. NaI crystal that is 12 inches long. Processing was done using a spectral stripping method. Coefficients for stripping are based on the API pits at the University of Houston for a water-filled borehole. The SWS tool 
uses a 1.75-inch NaI crystal that is 12 inches long (Serra and others, 1980). Elements are determined by a matrix operation on counts from five windows. Matrix coefficients are established for a water-filled 8-inch borehole.

Spectral gamma-ray logs are shown in figs. 10 and 11. The AWS curves are presented with much less averaging than the SWS curves. In particular, the uranium and thorium curves show a great deal more character on the AWS log than on the SWS log. As it turns out, the character reflects statistical variation rather than signal.

Repeat runs are disappointing. In particular, the uranium and thorium traces from the two AWS runs compare poorly (fig. 12) and will require substantial filtering before they are useful. Four runs were made with the SWS NGT tool (fig. 13) to test the effect of the source on the CNT-G, which was run in combination with the NGT. Apparently, the CNT-G had no effect upon the spectral results.

Even with substantial filtering, the SWS logs occasionally show small excursions which might appear to exceed statistical fluctuations, but which did not repeat on subsequent runs. Good examples are the negative excursion at 2,490 feet and the positive excursion at 2,530 feet, both in the potassium trace of fig. 13-c. The lack of repeatability displayed among the four runs in fig. 13 is puzzling because the differences occur at such long spatial wavelengths, on the order of 20 to 50 feet. One would expect that statistical fluctuations, which are largest at the scale of 1-foot samples, would decay away to very small values at the 20 - to 50 -foot scale, even allowing for the effect of spatial filtering.

Six "statistical checks" were made with the NGT tool held stationary in the hole while recording for 10 minutes. The checks were made before and after continuous logging ( $B$ and $A$ tests in table 5). The mean value and range were estimated visually from the log; the range is simply the difference between the minimum and maximum recorded during a 10-minute run. One would expect that the mean values on the before and after runs would fall within one-half range of one another. This is the case for the potassium values. However, the uranium tests do not repeat as well, nor do the thorium tests at B820 and A820 agree very well.

The effect of using algorithms set up for water-filled boreholes can be viewed in fig. 10 . The total gamma counts (track 2) undergo a marked offset at 1,750 feet as the tools come out of water. The offset can be seen on most of the elemental traces, for both AWS and SWS logs. The offsets at 1,630 feet, which are marred by the caliper effect at that depth, are due to higher potassium and thorium content in the unaltered welded tuff, as confirmed by analyses of core samples (circles in fig. 10). The analyses of $\mathrm{K}, \mathrm{U}$, and Th were done by the USGS using gamma-ray spectrometry on $600 \mathrm{~g}$ samples.

Given that spectral analysis in fig. 10 is based on water-filled, 8-inch boreholes, one expects the logs to agree closely with core analysis below 1,750 feet. Indeed the potassium trace from SWS (pota) overlies the core data almost exactly, but the AWS trace $(\mathrm{K})$ is $50 \%$ too low. Above 1,750 , the AWS trace approaches the core data, but this is probably fortuitous, due to the shift in air-filled hole. Both AWS and SWS uranium traces agree with the core data, but both the traces lie well below the thorium points in the water-filled borehole.

The spectral logs and core data in the air-filled borehole can be compared in fig. 11. As received from AWS, the spectral estimates were quite noisy, so a nine-point tapered filter was applied to obtain the traces shown in fig. 11; the SWS traces were not processed. The SWS potassium log (POTA) reads about one weight percent higher than the core samples; the AWS potassium trace $(K)$ reads about one weight percent lower. Visual comparison of the other logs shows that only the SWS thorium trace (THOR) agrees closely with the core data.

\section{Utility of Spectral Gamma Logs at Yucca Mountain}

There are two potential uses of spectral gamma ray logs for the Yucca Mountain Project. In some environments, uranium migrates in solution and redeposits along fractures, so that a spectral log can detect small uranium peaks at the fracture-borehole interface, if the redeposition occurred at sufficient time to allow reequilibration with the gamma-emitting daughter products. Examination of existing logs at known fractures has never shown such occurrences, however. Given the statistical noise level seen in the G-2 logs, it may be that any such occurrences on existing logs would be lost in statistical fluctuations. In either case, attempts to find fractures with uranium logs have been unsuccessful.

The second application involves the measurement of potassium and thorium to serve as geological markers and also for investigations of potassium migration. Our inspection of the logs has indicated that thorium variations generally track potassium variations and that potassium mimics the total count log. Consequently, it appears that the 


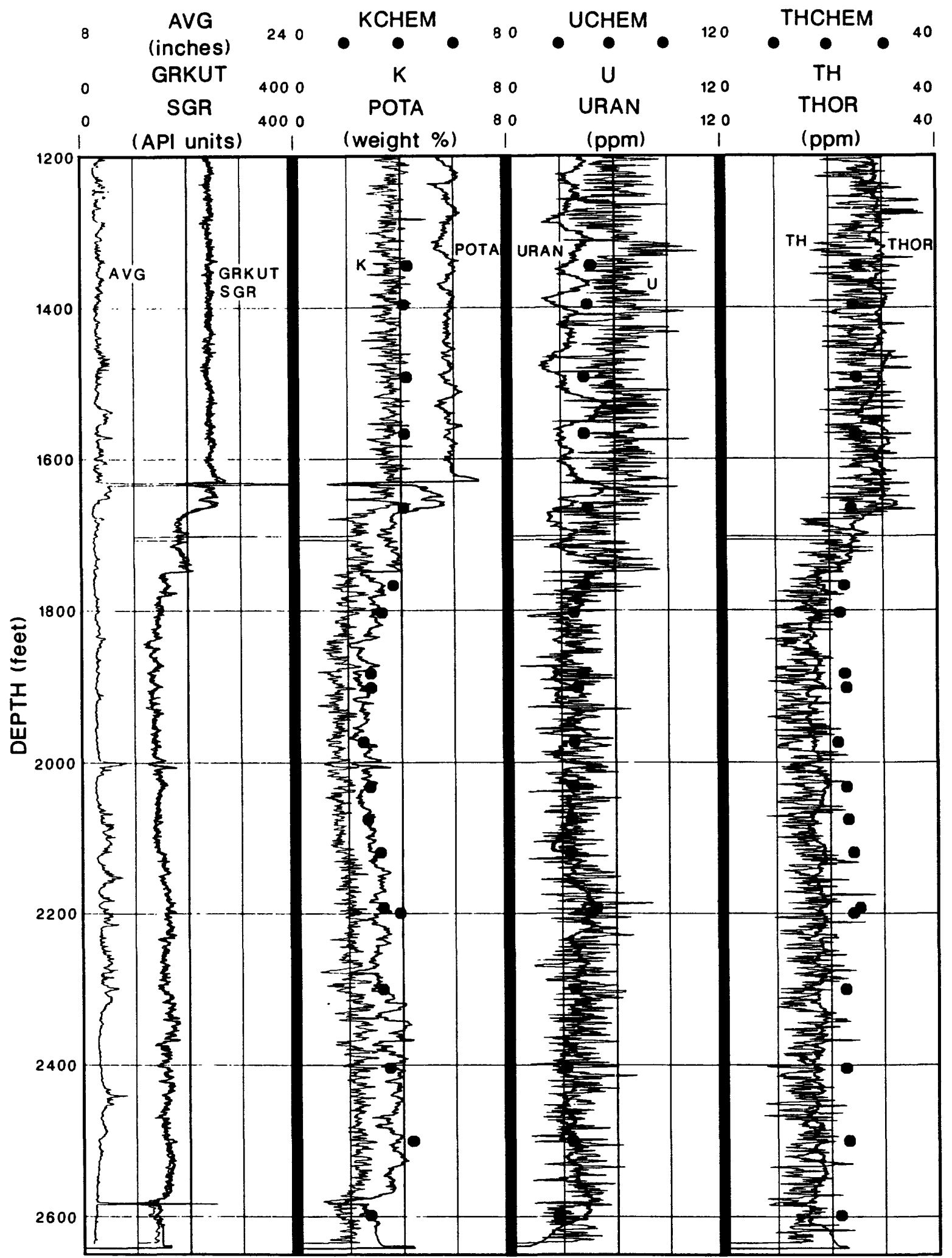

Figure 10.--Caliper (AVG), total gamma ray (SGR and GRKUT), and potassium, uranium, and thorium estimates from spectral gamma ray tools. K, U, and TH traces (light) are from AWS tool; POTA, URAN, and THOR traces (dark) are from SWS tool. Traces are uncorrected for air-filled borehole. KCHEM, UCHEM, THCHEM are from gamma-ray spectrometry on core samples. 


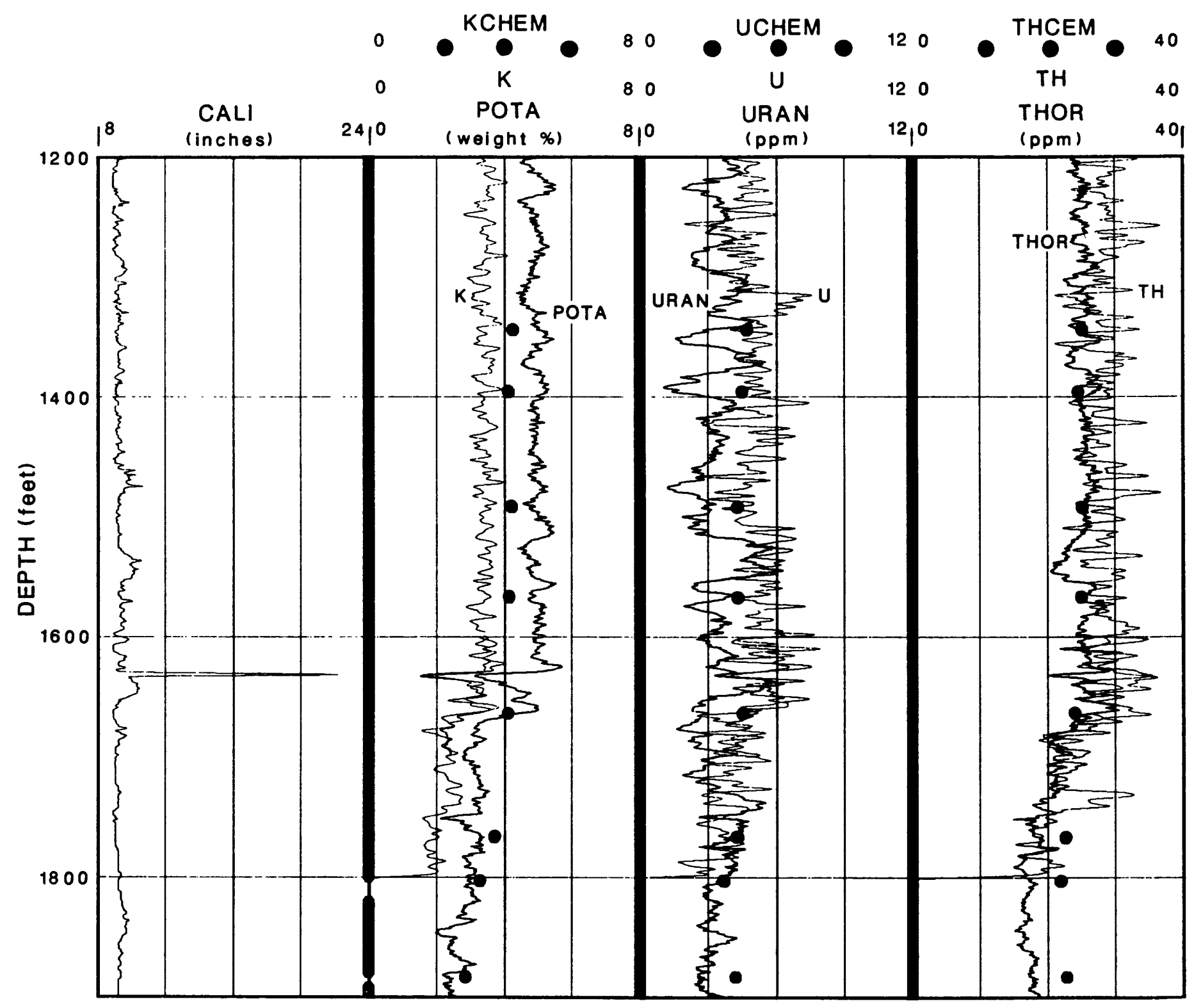

Figure 11.--Potassium, uranium, and thorium estimates from spectral gamma ray tools, in air-filled borehole. Traces have been corrected by AWS and SWS for air-filled borehole; compare with figure 10. The AWS traces (K, U, Th) have been filtered by the authors with a nine-point tapered filter. 


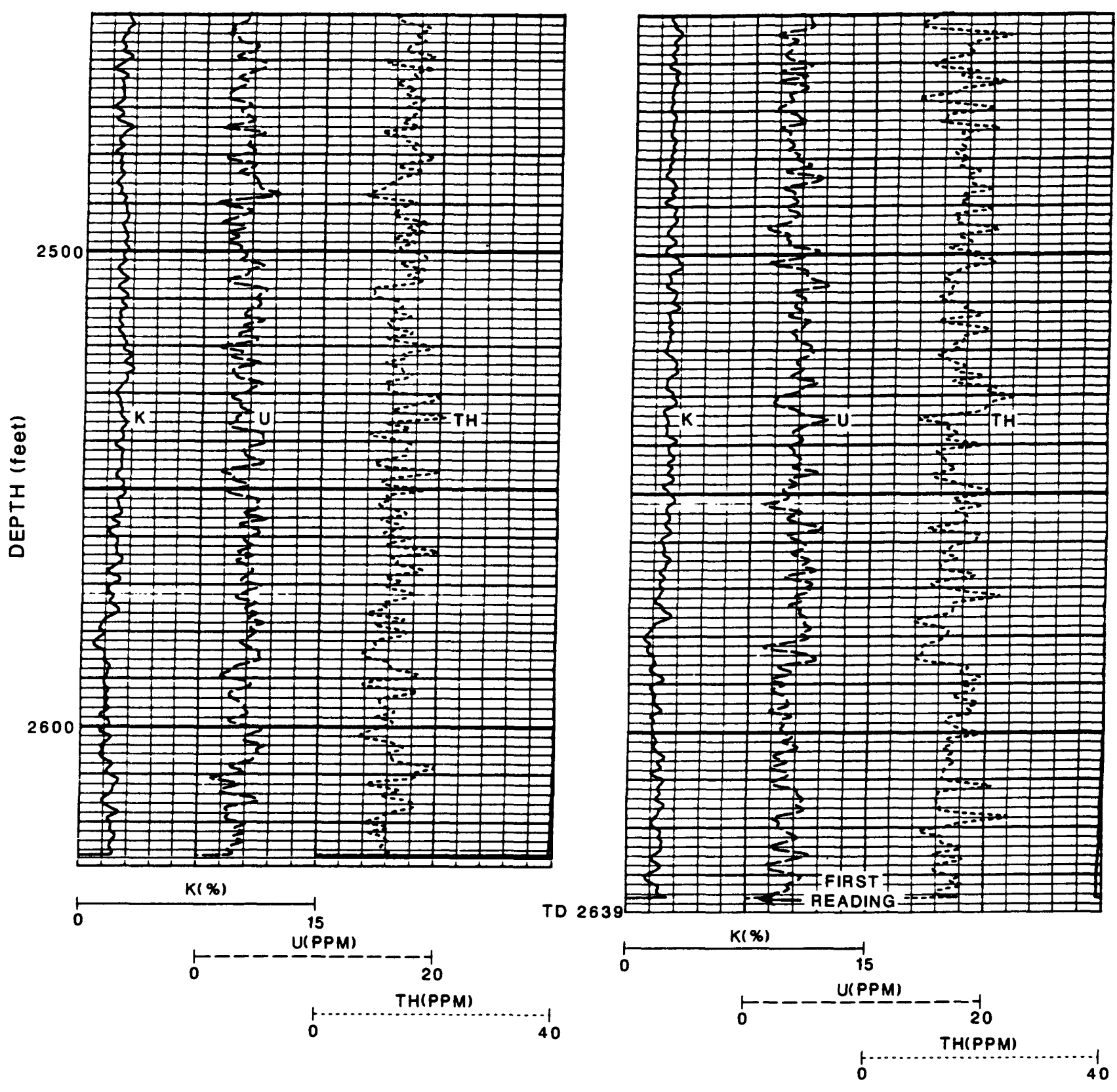

Figure 12.--Potassium, uranium, and thorium logs from AWS repeat run (left) and main run (right). Logging speed is 10 feet per minute. 


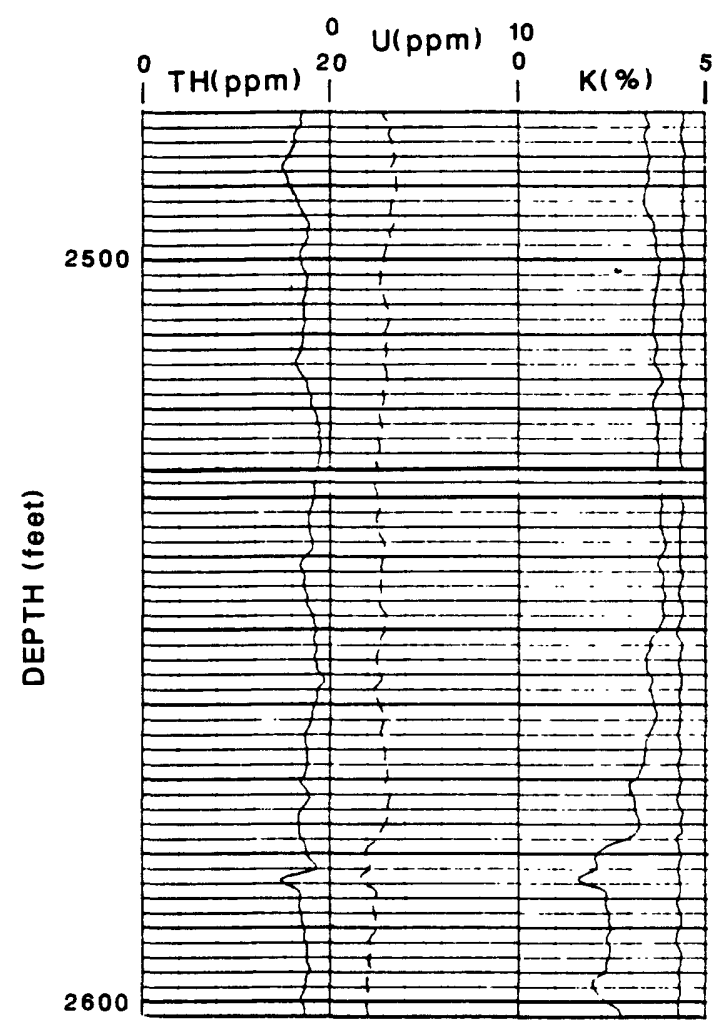

(a) MAIN PASS LOGGED AT $1800 \mathrm{FPH}$ BACKGROUND PASS

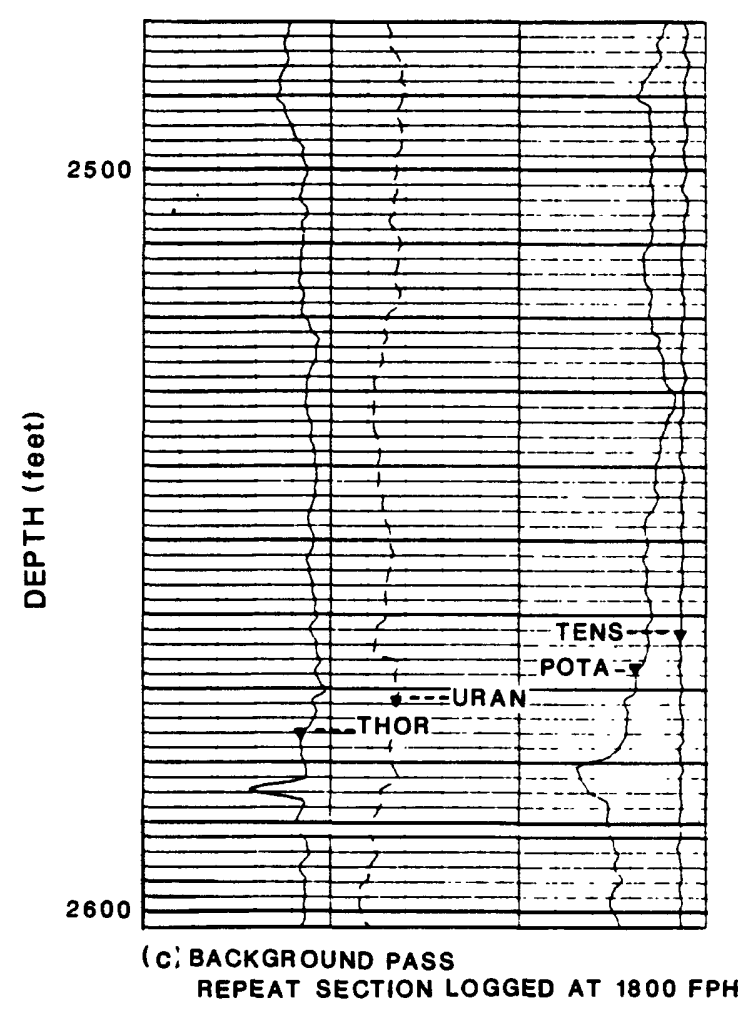

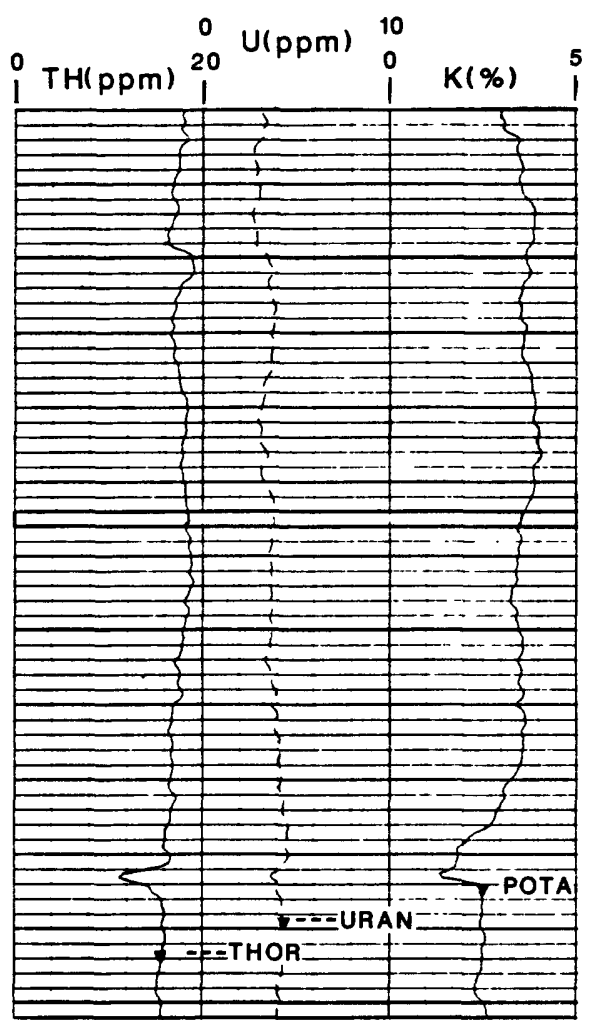

(b) MAIN PASS - (CNTG PRESENT)

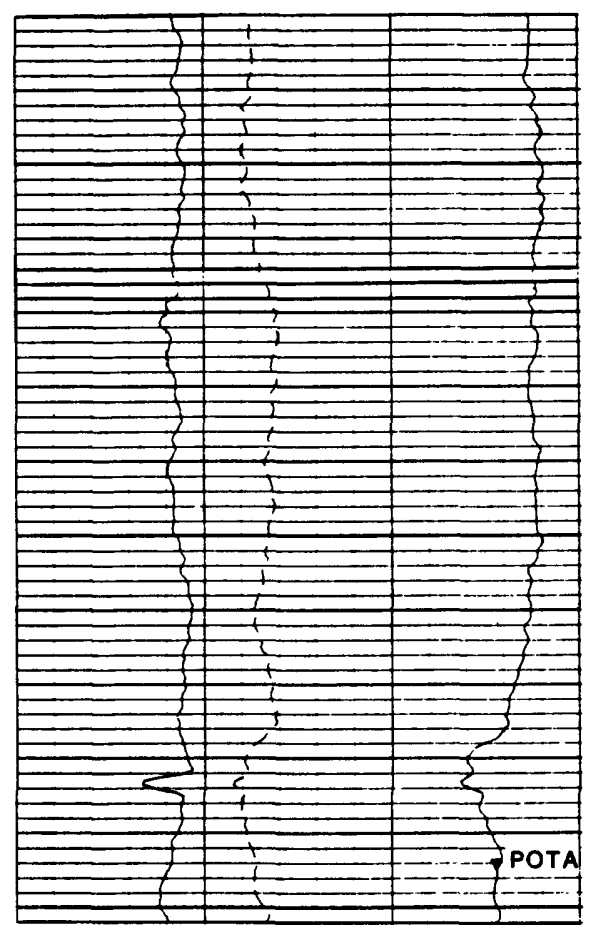

(d) REPEAT SECTION - (CNTG PRESENT)

Figure 13.--Thorium, uranium, and potassium logs from four SWS NGT runs, as labeled. Decreases at 2,583 feet occur at a borehole washout. 
Table 5.--Mean/range of thorium, uranium and potassium from 9-minute runs at selected depths using SWS's NGT tool. Mean and range are visual estimates. B=before logging; $A=$ after logging. Computations assumed water-filled boreholes

\begin{tabular}{|l|l|l|l|l|}
\hline Test & Detector depth & Thorium (ppm) & Uranium (ppm) & \multicolumn{1}{|c|}{$\begin{array}{c}\text { Potassium } \\
\text { (wgt \%) }\end{array}$} \\
\hline \hline B820 & 783 & $17.2 / 2.8$ & $6.0 / 2.0$ & $4.4 / 1.0$ \\
\hline A820 & 783 & $15.4 / 2.8$ & $7.4 / 2.0$ & $4.3 / 0.8$ \\
\hline B1098 & 1,061 & $28.0 / 5.2$ & $3.4 / 3.2$ & $5.7 / 0.8$ \\
\hline A1098 & 1,061 & $27.2 / 4.0$ & $5.5 / 2.0$ & $5 / 61.0$ \\
\hline B1800 & 1,763 & $16.4 / 2.4$ & $4.6 / 2.0$ & $3.2 / 0.8$ \\
\hline A1800 & 1,763 & $15.6 / 4.0$ & $5.6 / 2.6$ & $2.9 / 0.6$ \\
\hline scale & & 4 ppm/div & $2 \mathrm{ppm} / \mathrm{div}$ & $1 \% / \mathrm{div}$ \\
\hline
\end{tabular}

contribution of uranium to the total count gammaray log is small, and the total count log is adequate for qualitative tracking of lithological changes. Potassium migration studies, on the other hand, require reliable quantitative measurement of potassium. Based on the results shown here and on previous experience with AWS spectral logs, it appears unlikely that accurate elemental estimates have been obtained.

Better quantitative data could be obtained by running the logs slower, using a bigger crystal, and possibly by improving the software. But at the present, there is little motivation to continue running spectral gamma-ray logs at Yucca Mountain.

\section{Induction Logs}

Induction logs are shown in figures 14 and 15. We first discuss the SWS traces, then the AWS traces.

Three main passes were run with the SWS "phasor" induction tool, at frequencies of 10, 20, and $40 \mathrm{kHz}$ in both air-filled and water-filled borehole. The medium and deep curves processed with phasor deconvolution (Barber, 1985) are labeled IMPH and IDPH. We observe that on the 20 and $40 \mathrm{kHz}$ runs, the deep and medium curves, IDPH and IMPH, track one another quite well. However, at $10 \mathrm{kHz}$, the IMPH lies appreciably below the IDPH, and this gap increases as resistivity increases; this disparity is attributed to a measurement problem. We also found that the 10,20 and
$40 \mathrm{kHz}$ logs do not produce the same resistivity values, as shown in table 6.

It is believed that both these problems--the low value of the IMPH curve at $10 \mathrm{kHz}$ and the resistivity values varying with frequency are indicative of a problem in tool performance (T. Barber, SWS, written commun., 1992). It is especially noteworthy that these problems occurred even though a shop calibration was done just three days before the logs were run. All the parameters entered on the shop calibration are within range, that is, there are no indications that the tool was not performing within specifications at the time of the shop calibration.

Given the disparity among the three readings, which is the most reliable? Receiver voltage in an induction tool increases as the square of the frequency; the sensitivity is 5,20 , and $80 \mathrm{nV}$ per $\mathrm{mmho} / \mathrm{m}$ at 10,20 , and $40 \mathrm{kHz}$, respectively. Thus, the signal level at $40 \mathrm{kHz}$ is 16 times greater than at $10 \mathrm{kHz}$. Because the $40 \mathrm{kHz}$ signal is the strongest, it is likely that its offset is the least and that the $40 \mathrm{kHz}$ values are more nearly correct.

An understanding of signal and noise levels also helps to explain other phenomena observed on the logs. The $10 \mathrm{kHz}$ traces exhibit more detail than the $20 \mathrm{kHz}$ traces, and the 20 more than the 40 . At $1000 \mathrm{ohm}-\mathrm{m}$, equivalent to $1 \mathrm{mmho} / \mathrm{m}$, the $10 \mathrm{kHz}$ signal is 5 nanovolts. This happens to be roughly the electronic noise level of the tool. Consequently, the high frequency content of the $10-\mathrm{kHz}$ IMPH and IDPH traces is attributed to electronic noise, not geological signal. 


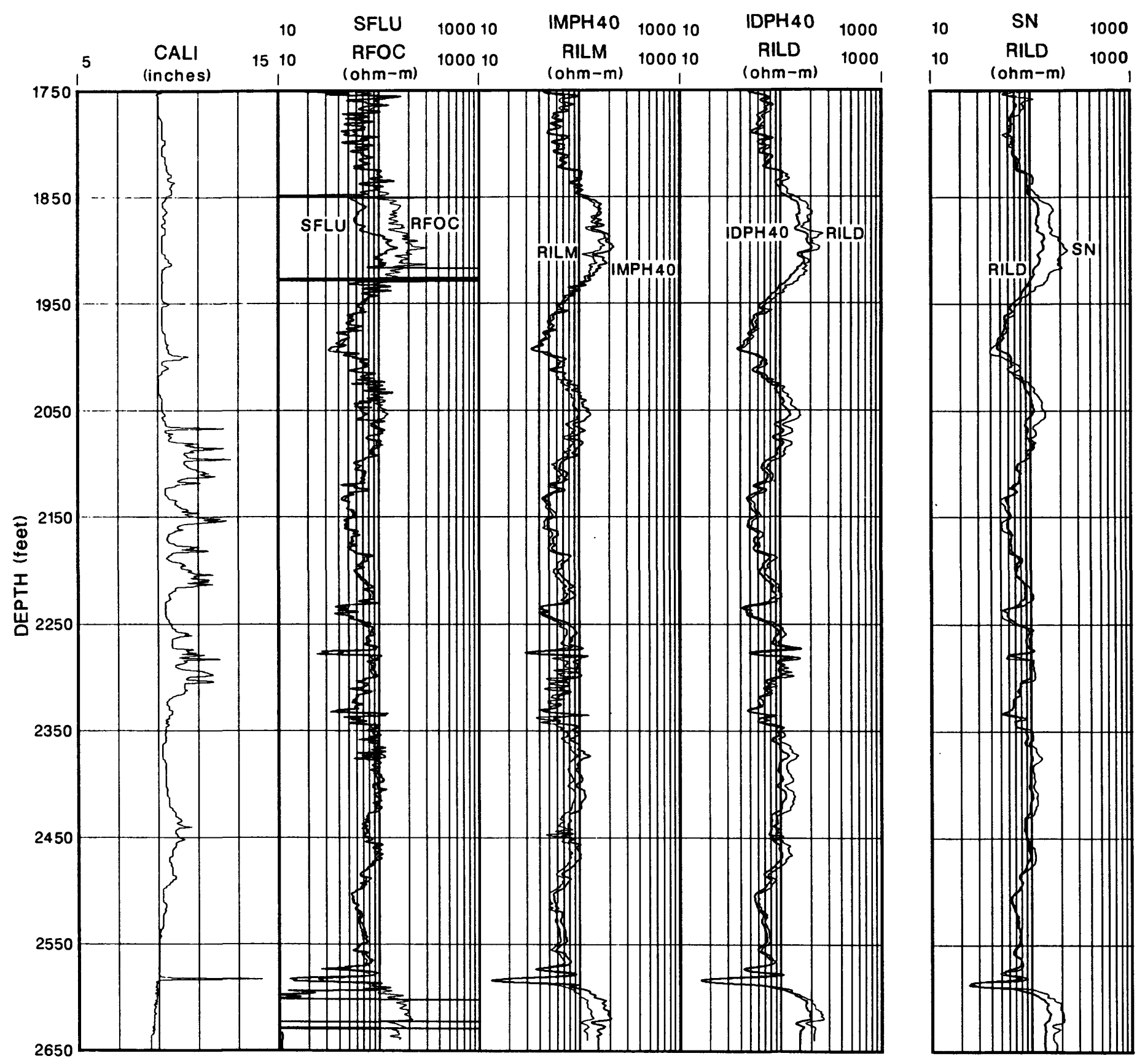

Figure 14.--Traces from induction tools run in the saturated zone by SWS (dark traces) and AWS (light traces). Caliper (CALI) from SWS. Shallow investigating focused logs are in track 2, medium induction in track 3 , and deep induction in track 4. Righthand track shows induction (RILD) and short normal (SN) logs from Birdwell tool run in 1981. 

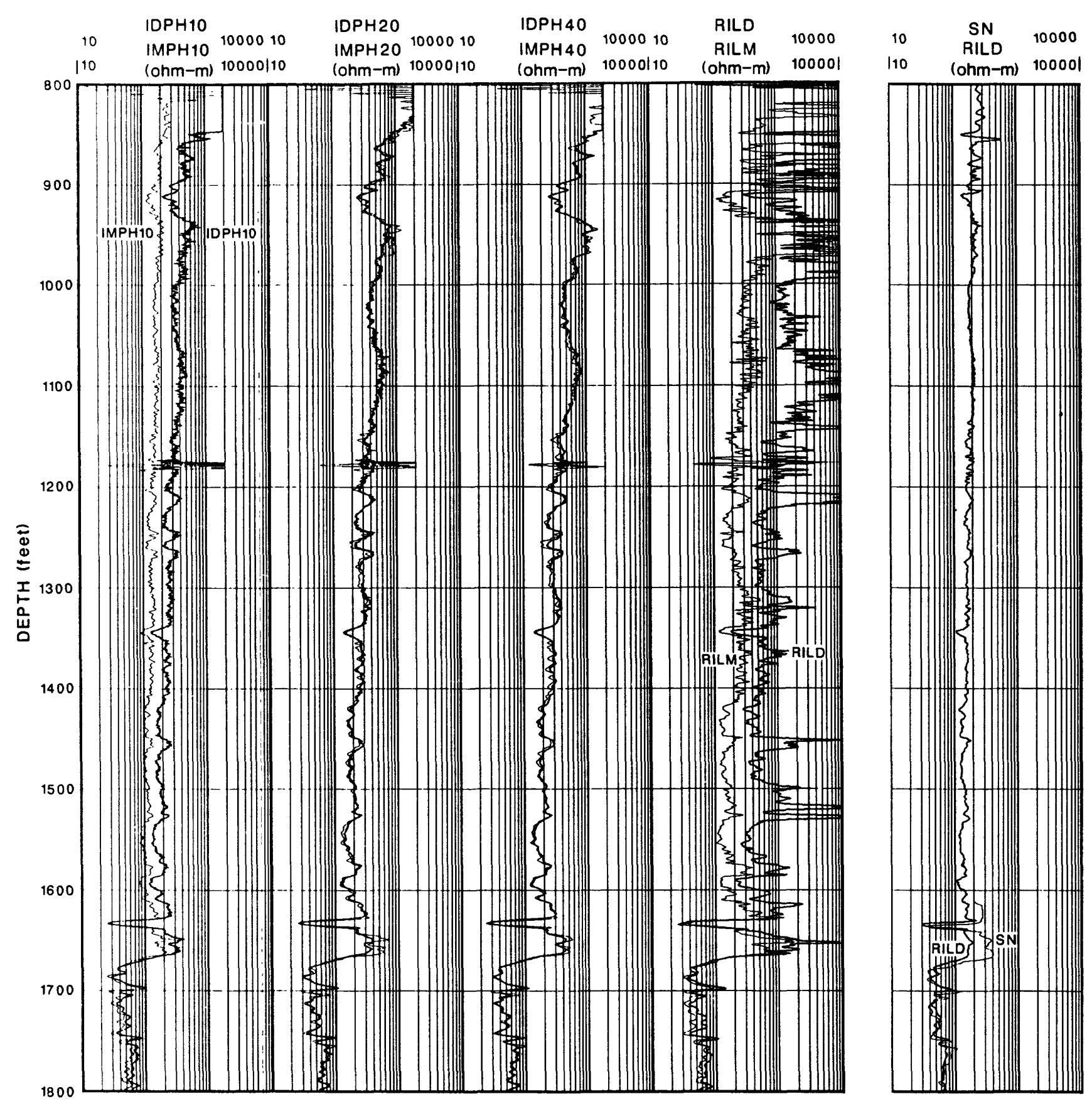

Figure 15.--Deep and medium induction logs run in the unsaturated zone by SWS (first three tracks), AWS (track 4), and Birdwell in 1981 (separate track at right). SWS logs were obtained at 10,20, and $40 \mathrm{kHz}$. 
Table 6.--Resistivity (ohm-m) and, in parentheses, conductivity ( $\mathrm{mmho} / \mathrm{m}$ ) from the SWS IDPH trace at three depths and three frequencies

\begin{tabular}{|l|l|l|l|}
\hline \multicolumn{1}{|c|}{ Depth (feet) } & \multicolumn{1}{c|}{$10 \mathrm{kHz}$} & \multicolumn{1}{c|}{$20 \mathrm{kHz}$} & \multicolumn{1}{c|}{$40 \mathrm{kHz}$} \\
\hline \hline 950 & $480(2.1)$ & $690(1.5)$ & $1000(1.0)$ \\
\hline 1,020 & $300(3.3)$ & $370(2.7)$ & $420(2.4)$ \\
\hline 1,540 & $130(7.7)$ & $140(7.1)$ & $130(7.7)$ \\
\hline
\end{tabular}

The SWS spherically focused log, SFLU, goes offscale in two intervals (1,916-1,930 feet and 2,600-2,630 feet in fig. 14) where all other logs are operating normally. Moreover, the field prints show that the SFLU goes offscale at different depths on the three separate $(10,20,40 \mathrm{kHz})$ runs. The operator attributed this response to "something within the borehole." Yet the six-arm caliper shows a very smooth borewall, and the AWS focused log, the RFOC, operates properly in the same interval. T. Barber (written commun., SWS, 1992) attributes the instability to the control circuitry of the SFLU, noting that the mud resistivity is greater than the 5 ohm-m limit specified for the tool. The tool, which is essentially a laterolog, requires a certain minimum current and hence a certain maximum resistance to operate properly. Within the SZ of borehole G-2, the combined conditions of high borehole fluid resistivity ( $\mathrm{Rw}>10 \mathrm{ohm}-\mathrm{m})$ and high formation resistivity appear to trigger the instability. Note that the tool becomes unstable as formation resistivity exceeds $100 \mathrm{ohm}-\mathrm{m}$. With this understanding, one can recognize another, more subtle, instability at $1,850-1,930 \mathrm{feet}$, where the SFLU reading drops well below the reading recorded by the induction and RFOC traces.

The AWS deep induction, RILD, is erroneous in the air-filled borehole (fig. 15); the values are much higher than any other induction log including the accompanying AWS RILM and the 1981 Birdwell induction log. It goes off-scale at $1,652,1,527$, 1,518 , and 1,451 feet, and at numerous places above 1,220 feet. The off-scale events occur in high resistivity zones, but the threshold level, around 200 to $400 \mathrm{ohm}-\mathrm{m}$ as measured by the RILM, is not consistent from one event to the next. It appears that the off-scale events are caused by a $3 \mathrm{mmho} / \mathrm{m}$ offset in the RILD (D. Hilliker, AWS, oral commun., 1992).
The AWS RILM values are consistently lower than the SWS values; for example, at 1,540 feet, RILM $=110$ while IMPH $=130 \mathrm{ohm}-\mathrm{m}$. We cannot say that one result is correct and another incorrect. Rather, these inconsistencies are indicative of difficulty in nulling small offsets at high resistivity.

In air, the AWS RILD and RILM both display higher spatial frequency content than in water; the logs display features with half-widths of 1 foot, which is unrealistic for induction tools. One suspects that either the AWS tools might be susceptible to near-wellbore effects or that we are again viewing electronic noise, as discussed above for the SWS tool.

The focused AWS log, the RFOC, operates properly in the water-filled hole (fig. 14). Its spatial definition and resistivity values are comparable to the SFLU run by SWS.

Also plotted in figs. 14 and 15 is the older Birdwell induction log acquired in May 1981. Its response is much more subdued than that of the other induction traces. The disparity is particularly noticeable in the higher resistivity of the UZ (fig. 15), where the Birdwell RILD log is noisier, has less character, and has values lower than the other logs; this character has been observed on the Birdwell induction logs obtained in the early 1980s (D. Muller, oral commun., USGS, 1992). At the higher conductivities below 1,680 feet, the Birdwell induction log does better at mimicking the other traces. By the way, one can see that the resolution of the 16-inch normal (SN) is comparable to a medium induction $\log$ and lacks the definition of the focused logs run by SWS and AWS.

In summary, neither company has a clearly superior induction tool in high resistivity environments. Extreme care must be used in establishing the zero conductivity reading in air. Performance of the AWS log was severely marred by a large offset. 
The higher frequency $(40 \mathrm{kHz})$ available on the SWS phasor tool makes it a good candidate for a high resistivity environment. If the SWS phasor induction is used, another shallow-investigating tool should be substituted for the spherically focused $\log$, which is erratic in resistive fluid. Phasor processing was developed to compensate for wave propagation effects in low resistivity environments; there is no need to apply it in the high resistivity ranges encountered at Yucca Mountain.

\section{Utility of induction logs at Yucca Mountain.}

Let us now discuss the advantages and disadvantages of the induction tool in terms of the characteristics of the unsaturated zone.

\section{Air-fllled borehole}

The greatest advantage, of course, is that induction tools can operate in air-filled boreholes where conventional electrode-based tools cannot operate.

\section{Rugose holes}

The borehole diameter varies considerably in the unsaturated zone. Induction tools can suffer from "cave effect" in resistive rock if the borehole is filled with conductive mud. Cave effect is caused by the contribution of the mud-filled pockets where the hole is enlarged; induction tools are particularly sensitive to near-borehole effects because the response factor of the tool is greatest at close range. However, because logs are run in air-filled holes in the unsaturated zone, there is no cave effect. In the $\mathrm{SZ}$, the induction tool remains immune to cave effect because the resistivity of the borehole fluid is higher than in most drilling muds, about $10 \mathrm{ohm}-\mathrm{m}$. So the induction tool has a real advantage because it is insensitive to borehole rugosity in both the UZ and $\mathrm{SZ}$.

\section{Resistivity range}

Resistivity values in the $\mathrm{UZ}$ range from less than $10 \mathrm{ohm}-\mathrm{m}$ in bedded tuffs to greater than $1,000 \mathrm{ohm}-\mathrm{m}$ in low-porosity welded zones. Induction tools work best in a moderate range of 1 to $100 \mathrm{ohm}-\mathrm{m}$ where skin-effect is minimal yet signals are still adequate. Above 200 to $500 \mathrm{ohm}-\mathrm{m}$, the signal strength drops to values low enough that accuracy degrades. Generally, a laterolog is pre- ferred in high-resistivity environs, but they cannot be used in the UZ because of the lack of borehole fluid. Thus, the high-resistivity regime is a disadvantage for operating an induction tool, as noted in the preceding discussion and figures.

\section{Shoulder beds (spatial resolution)}

The induction tool responds to a volume that is roughly 4 feet thick and 10 feet in diameter. In addition, contributions arise from rock units farther than the four-foot zone, particularly if the outlying (shoulder) beds are conductive. Vertical resolution is enhanced by numerical filtering called deconvolution. Even with deconvolution, some shoulder effect will occur. A good example occurs at 1,650 feet in G-2 (figs. 1 and 15) at the bottom of the Topopah Spring Member of the Paintbrush Tuff (Tpt), where the resistive vitrophyre is bounded above by bedded tuff and below by zeolitized tuff. The resistivity values from the deep and medium induction no longer agree, one sign that true resistivity was not measured. However, this example represents a rare case. Generally, on a scale of 10 to 50 feet within the UZ, resistivity varies by a factor of 2 to 3 . When variations are this modest, shoulder bed effects are negligible.

\section{Dip}

The geologic dip of 6 degrees at $\mathrm{YM}$ is so small that horizontal structures can be assumed in interpreting the induction response.

\section{Dielectric Logs}

\section{SWS Deep Propagation Log}

The SWS dielectric tool is a mandrel tool containing four receivers and one transmitter operating at $25 \mathrm{MHz}$ (Schlumberger, 1989). Transmitterreceiver spacings are not cited; one skin depth can be taken as an effective diameter of investigation which in $100 \mathrm{ohm}-\mathrm{m}$ rock is $1.01 \mathrm{~m}$. Phase shift and attenuation are measured between the near and far pairs of receivers and converted to resistivity and dielectric permittivity. Due to a software failure, field processing produced only phase shift and attenuation curves; subsequent processing in an SWS computing center produced the resistivity (DRDP) and dielectric traces (DEDP) shown in fig. 16. 


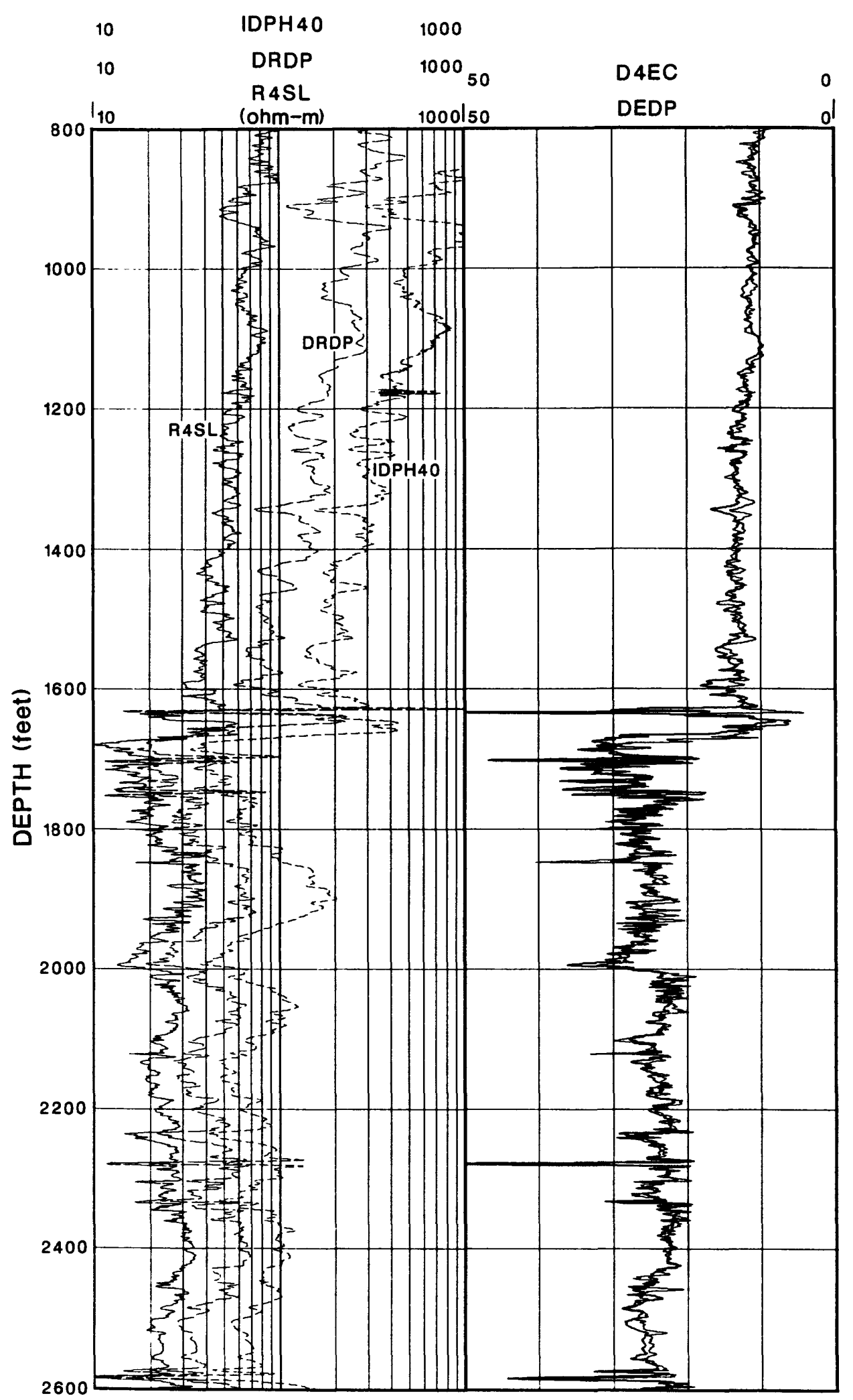

Figure 16.--Resistivity and dielectric logs at $25 \mathrm{MHz}$ by SWS (DRDP, DEDP) and at $47 \mathrm{MHz}$ by AWS (R4SL, D4EC). Also shown is the $40 \mathrm{kHz}$ induction resistivity by SWS (IDPH40). 


\section{AWS Dielectric Log}

The AWS dielectric tool is a mandrel tool containing two receivers and a transmitter operating at $47 \mathrm{MHz}$ (Lawrence and Fernandez, 1987). The two receivers are spaced 0.8 and $1.0 \mathrm{~m}$ from the transmitter. At 100 ohm-m, one skin depth is $0.73 \mathrm{~m}$, an indication of the diameter of investigation. Phase shift and attenuation are converted to resistivity (R4SL) and dielectric permittivity (D4EC) shown in fig. 16.

\section{Resistivity Values}

Resistivity measured at $25 \mathrm{MHz}$ (DRDP in fig. 16) is considerably less than that measured at $40 \mathrm{kHz}$ (IDPH40), and resistivity at $47 \mathrm{MHz}$ is considerably less than that measured at $25 \mathrm{MHz}$. For example, at 950 feet, R4SL reads $75 \mathrm{ohm}-\mathrm{m}$ and DRDP reads $200 \mathrm{ohm}-\mathrm{m}$, where IDPH40 is around $1,000 \mathrm{ohm}-\mathrm{m}$. This disparity appears to be an artifact of the way resistivity is obtained from the attenuation and phase measurements; resistivity obtained at these high frequencies contains contributions from the dielectric component and hence should not be used to compute water saturation using Archie's relationships.

\section{Comparison of Dielectric Logs}

The dielectric values from the AWS and SWS tools overlie one another reasonably well throughout the logged interval (fig. 16). Dielectric permittivity lies between 20 and 25 in the zeolitic rocks below 1,650 feet and decreases from 18 at the bottom ( 1,650 feet) of the welded sequence to 14 at the top ( 800 feet). The agreement between the two logs in both water-filled and air-filled boreholes is quite satisfactory. Either log can be used to measure dielectric permittivity at Yucca Mountain.

\section{Utility of Dielectric Logs at Yucca Mountain}

Based on preliminary calculations using a constitutive model referred to as the "complex refractive index method" (Shen and others, 1985), we have obtained reasonable values of water saturation using dielctric logs obtained in previous years at Yucca Mountain. Sherman (1990) used an alternative model based on the Hanai-Bruggeman equation to evaluate logs obtained at $47 \mathrm{MHz}$. Based on these experiences and on the similarity between the epithermal neutron and dielectric logs (fig. 1), we emphasize that the dielectric tool is a top priority for logging in the UZ at Yucca Mountain.

\section{EVALUATION}

1. Caliper. The six-arm caliper run by AWS does provide information on borehole eccentricity not provided by other single-arm calipers. It is desirable, but not mandatory, that the six-arm caliper continue to be run at Yucca Mountain.

2. Gamma-gamma Density. The AWS "ZDEN" trace and the SWS "RHOB" trace provide comparable, but not equivalent, estimates of density. The effect of an air-filled hole appears to be small and about the same on both tools (neither company provided an on-line algorithm for airfilled boreholes). Spatial resolution is better on the SWS tool; as a consequence, both low-density and high-density readings are more pronounced, and the SWS trace appears to be in somewhat better agreement with core data than the AWS trace. The better spatial resolution is offset by higher amplitude lowdensity spikes. Neither tool offers a clear advantage for use at Yucca Mountain.

3. Gravimeter. The borehole gravimeter provides a very useful complement to the density log in the UZ. We anticipate that the gamma-gamma density logs will always be plagued with lowdensity spikes in the UZ; therefore the gravimeter should be run routinely. Because independent determination of free-air gradient is so difficult, the gravimeter should be run into the water-filled portion of each borehole so it can be tied to the density $\log$ in water-filled holes.

4. Photoelectric effect. The information provided by the photoelectric traces may not have application at Yucca Mountain because other tools are more effective at defining lithology. However, because the photoelectric log is easily obtained in combination with density logs, it seems prudent to obtain a few more to evaluate their effectiveness.

5. Epithermal Neutron. All three epithermal neutron tools provided valid data in the SZ, but only the SNP run by SWS provided quantitative estimates of hydrogen (water) content. Its agreement with core porosity values is quite encouraging.

6. Thermal Neutron. The thermal neutron tools did not provide data in the air-filled borehole; poor quality in the water-filled borehole penetrating zeolitized tuff is attributed to low count rates. Because thermal neutron logs do not function in airfilled boreholes, it is recommended that a thermal neutron $\log$ be run only if a borehole penetrates a 
significant distance (say, 200 feet) into the saturated zone. We emphasize that these remarks apply only to the long-spaced thermal neutron systems and not to the short-spaced (moisture meter) systems.

7. Induction. Both companies had difficulty obtaining repeatable measurements in the highresistivity UZ. However, the high frequency $(40 \mathrm{kHz})$ induction tool provided by SWS offers a higher signal/noise ratio, so that with proper care in site calibration, it appears to offer potential for improved resistivity measurements in the UZ. The "phasor processing" offered by SWS provides no advantage in a resistive environment and should not be done.

8. Resistivity. The focused $\log$ (SFLU) run by SWS either failed or provided erroneous data in the SZ. Because both rock and borehole fluid are highly resistive, the shallow-investigating resistivity tool should be of a non-focusing (non-laterolog) type.

9. Dielectric. The 25-MHz SWS and the 47$\mathrm{MHz}$ AWS tools produced comparable and realistic values of dielectric permittivity. Because the dielectric tool appears promising for determination of water content, it is a high priority log for Yucca Mountain.

10. Gamma-ray Spectrometry. The SWS potassium and uranium traces below the water table matched the core data quite well; the AWS uranium trace matched the core data but requires additional smoothing. Above the water table, only the SWS thorium log matched the core data. In sum, present logs are unsatisfactory both in terms of accuracy and repeatability. Because the potassium, uranium, and thorium data are most useful at Yucca Mountain if they are accurate, strenuous efforts should be made to improve accuracy, especially in the air-filled boreholes.

11. Magnetic Properties. Variations in magnetic properties provide excellent markers for stratigraphic correlation of ash-flow tuffs (see fig. 11 and discussion in Nelson, Muller, and others, 1991). In particular, the remanent magnetization provides a record of the earth's field at the time of deposition. At Yucca Mountain, the remanent field is so strong that it is easily recognized with a borehole magnetometer. The magnetic susceptibility provides a useful complement to the magnetic field measurement. These measurements need to be done routinely in future boreholes at Yucca Mountain.

12. Borewall imaging. Detection of fractures is most important; the most practical and effective method of imaging the borewall is a television camera (Nelson, Snyder, and Kibler, 1991).
Although television has not been evaluated in this report, we urge that acquiring and reducing television images be considered, and that a method of ascertaining fracture dip be developed.

13. Calibration and Continuity. It is important to maintain consistency in the logging program. Ideally, the same tool model, and even the same tools should be used throughout the program. But more important is the need to maintain a consistent and workable calibration program. Here, the term "calibration program" is interpreted rather broadly, to incorporate the usage of algorithms for the reduction of data in air-filled boreholes. The company providing the log should be responsible for the development and application of the correct algorithm for reducing data in air-filled boreholes. Because a great deal of core will be collected and analyzed in future drilling, there will be ample opportunity to verify the accuracy of the logs. The combination of conscientious tool calibration and cross-checks with core data offers the best combination to provide reliable logs.

14. Future Logging. Although a fair portion of the logging done in the past was done in the SZ, this is unlikely to be true in the future. A list of 31 proposed boreholes to be drilled to depths of 1,500 to 5,000 feet shows that only three will penetrate more than a few hundred feet below the static water level. Of these three, boreholes G-5 and G-6 are expected to be 4 inches in diameter, which will preclude use of many commerically available tools. Because future logging will be so heavily concentrated in air-filled boreholes, it is recommended that planning and preparation for logging be geared to the air-filled borehole.

\section{ACKNOWLEDGMENTS}

Bud Thompson of SAIC initiated the logging of borehole G-2. Bill Mountjoy, Darrel Trcka, Don Hilliker, Don Oliver, and Alan Gilchrist of AWS and Tom Barber of SWS have contributed knowledge and specifications regarding the logging tools. Chuck Bush of the USGS performed the laboratory analyses of potassium, uranium and thorium. Reviews by John Conaway of Los Alamos National Laboratory and Alan Flint of the USGS led to improvements in the text. 


\section{REFERENCES CITED}

Barber, T., 1985, Real-time environmental corrections for the DIT-E Phasor dual induction tool: Society of Professional Well Log Analysts Twenty-sixth Annual Logging Symposium, paper EE, 15 p. (NNA.921113.0002)

Bish, D.L. and S.J. Chipera, 1989, Revised mineralogic summary of Yucca Mountain, Nevada, Los Alamos National Laboratory, LA-11497-MS, 68 p. (NNA.880728.0014)

Butsch, R.J. and H.L. Vacca, 1990, Experimental pulsed neutron porosity for gas-filled boreholes in the Gulf Coast, SPE paper 20588, pp 619-627. (NNA.921118.0003)

Edcon, Inc., 1991, Report on a borehole gravity survey in the USW-G2 Well, Nevada Test Site, Denver, 94 p. (NNA.910502.0061)

Ellis, Darwin V., 1990, Neutron and gamma ray scattering measurements for subsurface geochemistry, Science, v. 250, pp. 82-87. (NNA.921113.0004)

Flaum, C., 1983, Dual detector neutron logging in air filled boreholes, in Society of Professional Well Log Analysts Twenty-fourth Annual Logging Symposium, paper BB, 21 p. (NNA.921118.0004)

Flaum, C., J.M. Holenka, and C. Case, 1991, Eliminating the rugosity effect from compensated density logs by geometrical response matching, SPE Formation Evaluation, June, pp. 252-258. (NNA.921113.0006)

Galford, J.E., Nelson, R.F., and McKeon, D.C., 1991, A ratio-based epithermal neturon porosity for airfilled boreholes, SPE Paper 23427, Soc. Petr. Engr. Eastern Regional Meeting, October, pp. 131-142. (NNA.921118.0005)

Lawrence, T., and Fernandez, J., 1987, Simplified dielectric log interpretation in variable salinities using resistivity versus phase angle crossplots: Society of Professional Well Log Analysts Twenty-eighth Annual Logging Symposium, paper L, 23 p. (NNA.921118.0006)

Maldonado, Florian, and Koether, S.L., 1983, Stratigraphy, structure, and some petrographic features of Tertiary volcanic rocks at the USW G-2 Drill Hole, Yucca Mountain, Nye County, Nevada: U.S. Geological Survey Open-File Report 83-732, 83 p. (NNA.870506.0143)

Montazer, Parviz and William E. Wilson, 1984, Conceptual hydrologic model of flow in the unsaturated zone, Yucca Mountain, Nevada, U.S. Geological Survey Water-Resources Investigations Report 844345, 55 p. (NNA.870519.0109)

Muller, D.C. and Spengler, R.W., 1989, Bulk porosity in lithophysal zones above the static water level calculated from borehole gravity and gammagamma density logs at Yucca Mountain, Nevada, in International Symposium on Borehole Geophysics for Minerals, Geotechnical, and Groundwater Applications, 3d, Las Vegas, NM, October 1979, Proceedings: Society of Professional Well Log Analysts, p. 29-52. (NNA.890725.0015)

Nelson, P.H., Muller, D.C., Schimschal, Ulrich, Kibler, J.E., 1991, Geophysical logs and core measurements from forty boreholes at Yucca Mountain, Nevada: Geophysical Investigations Map GP1001, 64 p., 40 plates. (NNA.920211.0022)

Nelson, P.H., R. Snyder, and J.E. Kibler, 1991 Fracture counts from borehole logs, in U.S. Geological Survey Committee for the Advancement of Science in the Yucca Mountain Project Symposium on "Fractures, Hydrology, and Yucca Mountain": Abstracts and Summary, Joan Gomberg, editor, U.S. Geological Survey Open-file Report 91-125, 38 p. (NNA.921113.0017)

Nelson, P.H., and Anderson, L.A., 1992, Physical properties of ash-flow tuff from Yucca Mountain, Nevada, Journal of Geophysical Research, in press. (NNA.920707.0061)

Nimick, F.B., and Schwartz, B.M., 1987, Bulk, thermal, and mechanical properties of the Topopah Spring Member of the Paintbrush Tuff, Yucca Mountain, Nevada, Sandia National Laboratories, SAND850762, UC-70, 251 p. (NNA.870723.0015)

Robison, J.H., D.M. Stephens, R.R. Luckey, and D.A. Baldwin, 1988, Water levels in periodically measured wells in the Yucca Mountain area, Nevada, 1981-87, U.S. Geological Survey Openfile Report 88-468, 132 p. (NNA.890306.0113)

Schlumberger, 1989, Log Interpretation Principles/ Applications, Schlumberger Educational Services, Houston, 223 p. (NNA.921118.0007)

SAIC, 1991a, Borehole logging (1991), USW G2 at Yucca Mountain, Nevada, Logger's Log, January, 60 p. (NNA.921118.0008-0009) 1991b, Borehole logging (1991), USW G2 at Yucca Mountain, Nevada, Operations Report, January, 33 p. (NNA.921118.0010)

Serra, O., Baldwin, J., and J. Quirein, 1980, Theory, interpretation and practical applications of natural gamma ray spectroscopy, Society of Professional Well Log Analysts Twenty-First Annual Logging Symposium, paper Q, 30 p. (NNA.921113.0022)

Shen, L.C., Savre, W.C., Price, J.M. and K. Athavale, 1985, Dielectric properties of reservoir rocks at ultra high frequencies, Geophysics, 50, 4, April, pp. 692-704. (NNA.921113.0023) 
Sherman, M.M., 1990, Interpretation of dielectric permittivity measurements in the $20-$ to $50-\mathrm{MHz}$ frequency range, SPE Formation Evaluation, March, p. 76-80. (NNA.921113.0024)

Tittman, J., 1956, Radiation logging: physical principles, Univ. of Kansas Petroleum Engineering Conference, 20 p. (NNA.921118.0012)

U.S. Department of Energy, 1988, Site Characterization Plan, Yucca Mountain Site, Nevada research and development area, Nevada: U.S. Department of Energy Report DOE RW/0199, v. IV, pt. B, p. 8.3.1.4-57-59. (HQO.881201.0002)

Note: Parenthesized numbers following each cited reference are for U.S. Department of Energy Office of Civilian Radioactive Waste Management records management purposes only and should not be used when ordering the publication. 
The following number is for U.S. Department of Energy Office of Civilian Radioactive Waste Management records management purposes only and should not be used when ordering this publication: Accession number NNA.921211.0173 